\title{
The crystal-chemical autopsy of octahedral sites in Na-dominant tourmalines: octahedral metrics model unconstrained by the Y,Z-site disorder assignment
}

\author{
Peter BAČÍK ${ }^{1,2}$
}

\author{
${ }^{1}$ Department of Mineralogy and Petrology, Faculty of Natural Sciences, Comenius University, Ilkovičova 6, 84215 Bratislava, Slovakia; \\ peter.bacik@uniba.sk \\ ${ }^{2}$ Earth Science Institute of the Slovak Academy of Sciences, Dúbravská cesta 9, 84005 Bratislava, Slovak Republic
}

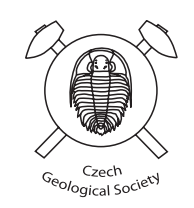

\begin{abstract}
The structure of tourmaline-supergroup minerals includes two types of octahedral sites: the $\mathrm{ZO}_{6}$ octahedron is smaller and more distorted than the $\mathrm{YO}_{6}$ octahedron. The octahedral sites metrics were studied and their dependency on the chemical composition unconstrained by $Y, Z$-site disorder assignment. Published chemical and structural data were collected from American Mineralogist Crystal Structure Database for tourmaline samples belonging to dravite-schorl, schorl-elbaite (including tsilaisites) and schorl ( \pm dravite)-olenite series. Correlation analysis of this dataset provided the evidence of cation distribution between sites - $\mathrm{Al}$ and $\mathrm{Mg}$ are disordered between $Z$ and $Y$ sites, while Fe (mostly ferrous), $\mathrm{Li}$ and Mn strongly prefer $Y$ site. Irregular cation distribution results in the variable metrics of both octahedra in tourmalines. It is the function of well-balanced relations between cations at octahedral and neighbouring sites based on bond-valence variations due to different ionic charges. Considering $Z$ and $Y$ cations, there is a dependence of the cation charge difference and the octahedral metrics. The most pronounced irregularity of both octahedra was observed in elbaite samples with the largest charge difference between Li and Al. In contrast, "buergerite" samples with trivalent Fe and Al at both octahedral sites have both octahedra almost isometric. Schorl and dravite samples display an increasing metric irregularity related to the $\mathrm{Al}$ and $\mathrm{Mg}$ content; increase in $\mathrm{Mg}$ reduces irregularity because $\mathrm{Mg}$ is distributed between both octahedral sites balancing charge difference. In contrast, Fe-rich and Al-rich schorl samples display larger irregularity which may result from selective incorporation of $\mathrm{Fe}^{2+}$ to the $Y$ site. In olenite samples, the irregularity of both octahedra decreases with an increasing $\mathrm{Al}$ content. These variations are related to the shared edge of $\mathrm{ZO}_{6}$ and $\mathrm{YO}_{6}$ octahedra including both $\mathrm{O} 3$ and O6 site where bonds of both anions are balancing bond-valence requirements of the stable electroneutral structure. In addition to the bond-valence relations, effects of the internal geometry of atomic shells should be also considered, i.e. Jahn-Teller distortion that can be decisive factor in cation occupancy. Especially $\mathrm{Fe}^{2+}$ can strongly prefer $\mathrm{YO}_{6}$ octahedron whose prolonged tetragonal dipyramidal geometry is more favourable for $\mathrm{Fe}^{2+}$ in $\left(\mathrm{t}_{2 \mathrm{~g}}\right)^{4}\left(\mathrm{e}_{\mathrm{g}}\right)^{2}$ configuration.
\end{abstract}

Keywords: tourmaline supergroup, octahedral metrics, bond-valence theory, Jahn-Teller effect

Received: 6 October 2017; accepted: 31 May 2018; handling editor: J. Cempirek

The online version of this article (doi: 10.3190/jgeosci.260) contains supplementary electronic material.

\section{Introduction}

The structure of tourmaline-supergroup minerals with the general formula $X Y_{3} Z_{6}\left(T_{6} \mathrm{O}_{18}\right)\left(B \mathrm{O}_{3}\right)_{3} V_{3} W$ includes two types of octahedral sites (Henry et al. 2011). The $\mathrm{ZO}_{6}$ octahedron is smaller than the $\mathrm{YO}_{6}$ octahedron and is more distorted (Henry and Dutrow 1996). Although the $Z$ site is predominantly occupied by trivalent cations, usually $\mathrm{Al}$, some tourmaline end-members have $\mathrm{Cr}, \mathrm{V}$, or $\mathrm{Fe}^{3+}$ as the dominant $Z$-site cation accompanied by $\mathrm{Mg}$. Moreover, some Ca-dominant tourmalines have $Z$-sites occupied by both $\mathrm{Mg}$ and $\mathrm{Al}$ (Henry et al. 2011) and ${ }^{\mathrm{Z}} \mathrm{Mg}$ occupancy also can increase due to Al-Mg disorder (Hawthorne et al. 1993). The $Y$ site can accommodate a larger range of valences of available elements such as monovalent $\mathrm{Li}$, divalent $\mathrm{Fe}, \mathrm{Mg}$, $\mathrm{Mn}$, trivalent $\mathrm{Fe}, \mathrm{Al}, \mathrm{Cr}, \mathrm{V}$ and tetravalent $\mathrm{Ti}$ and also vacancies (Henry et al. 2011), although Ti structural position is not clear yet.

Although the site occupancy usually follows Goldschmidt rules (ionic radii of cations occupying the $Z$ site are lower and therefore the $\mathrm{ZO}_{6}$ octahedron is smaller), local structural and bond-valence requirements may result in various cation disorder. Along with the $\mathrm{Al}-\mathrm{Mg}$ disorder (Hawthorne et al. 1993), the $\mathrm{Cr}$ and $\mathrm{V}$ disorder between $Y$ and $Z$ sites was documented (Bosi et al. 2004; Cempírek et al. 2013; Bosi et al. 2017).

The order-disorder reactions were previously studied in detail by structure refinement methods (Grice and Ercit 1993; Hawthorne et al. 1993; Bloodaxe et al. 1999; Ertl et al. 2003, 2010, 2012; Bosi and Lucchesi 2004; Marschall et al. 2004). More general statistical approach was applied on $\mathrm{Mg}, \mathrm{Al}$ and $\mathrm{Fe}$ ordering at octahedral sites in schorl-dravite series (Bačík 2015). Here, the 


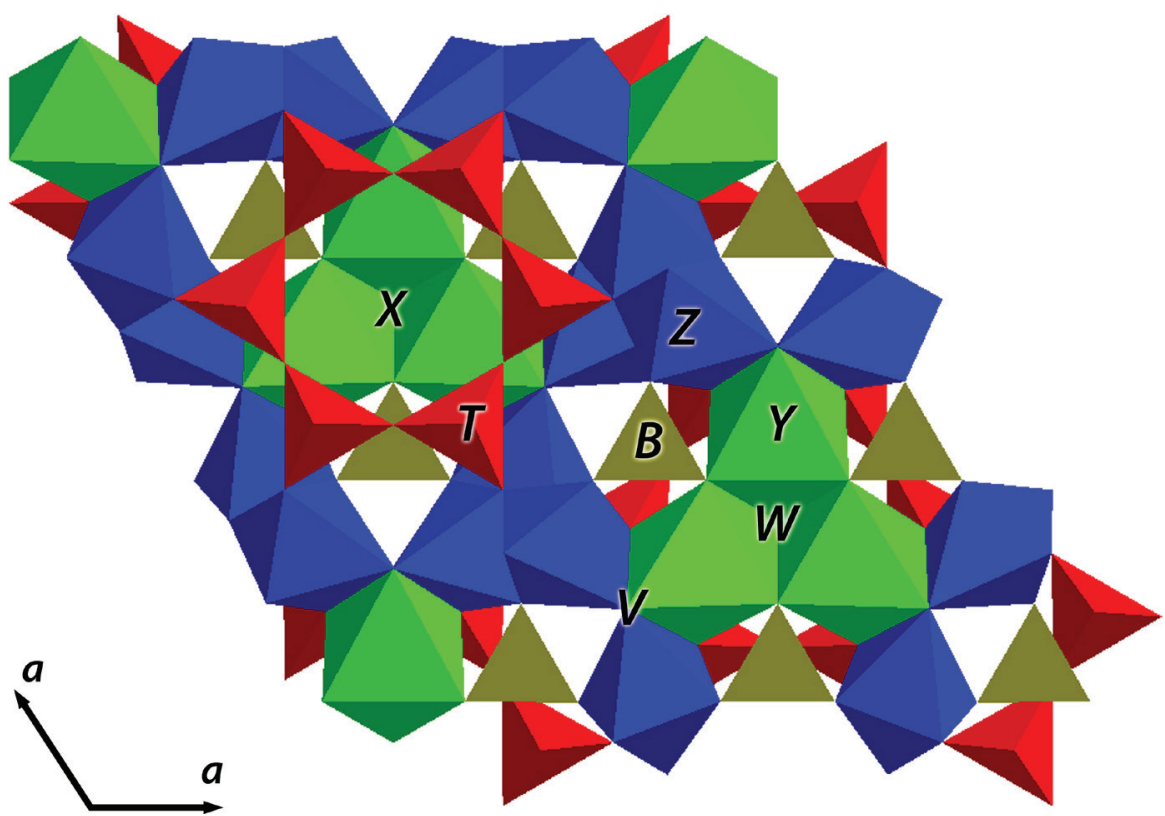

Fig. 1 Structure of tourmaline-supergroup minerals. focus is broadened to include other $\mathrm{Na}$ - and Al-dominant tsilaisitic-elbaitic, olenitic and buergeritic tourmalines (including those artificially prepared by heating experiments that, however, may not be stable regarding bond lengths and disorder). The mutual dependence of selected octahedral bond lengths, bond-valences, octahedral metrics and the site occupancy is studied. This allowed to

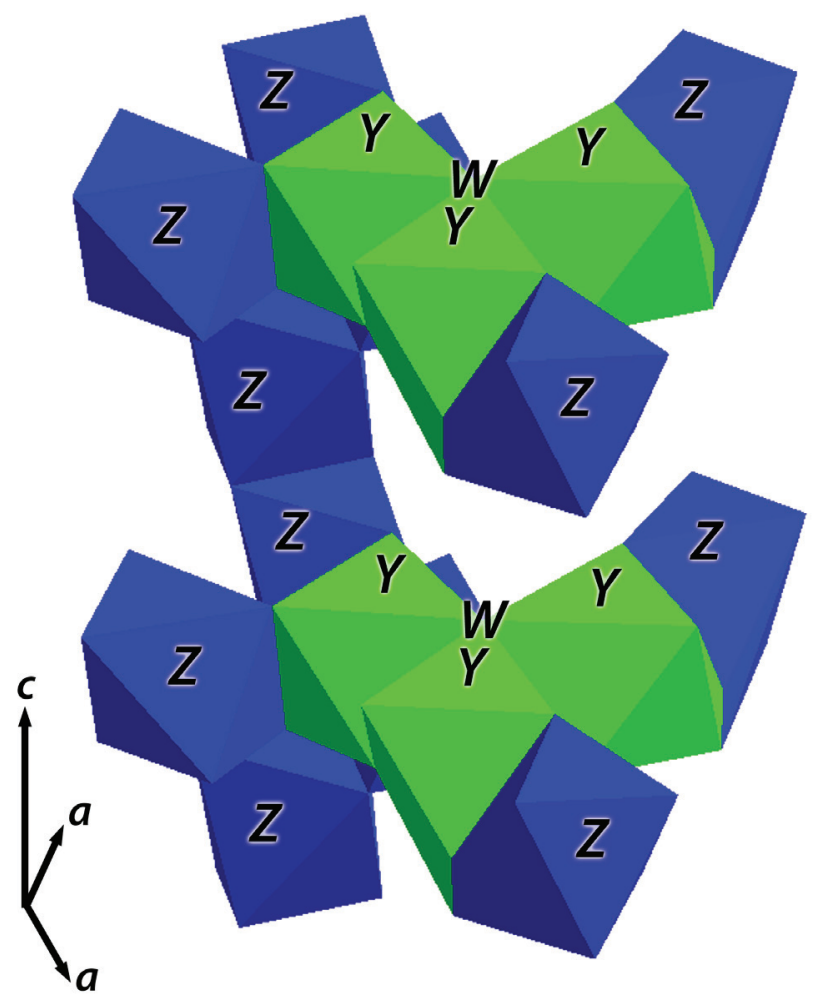

Fig. 2 Framework of $\mathrm{ZO}_{6}$ sites connected to triplets of $\mathrm{YO}_{6}$ octahedra. assess structural factors contributing to geometry of the octahedral sites in Na-dominant tourmalines.

\section{Tourmaline crystal structure}

Tourmaline-supergroup minerals are cyclosilicates with a relatively complex structure (Fig. 1). The oldest published structure analysis of tourmalines featured five different cation sites of variable coordination - one tetrahedral $T$ site, two octahedral $Z$ and $Y$ sites, polyhedral $X$ site, triangular B site, and eight different anion sites - O1-O8 (Hamburger and Buerger 1948; refined by Ito and Sadanaga 1951). The "Buerger" structure is accepted until now. The tourmaline structure can be described as the $3 \mathrm{D}$ framework of edge-connected $\mathrm{ZO}_{6}$ octahedra, interconnected by regularly distributed structural "islands" (Fig. 2). These comprise six-member rings of $\mathrm{TO}_{4}$ tetrahedra, triplets of $\mathrm{YO}_{6}$ octahedra, large 9-coordinated $X$ sites and $\mathrm{BO}_{3}$ triangles (Bosi 2017).

\subsection{Cationic sites}

The most prominent feature of the tourmaline structure is represented by the ring of six $T \mathrm{O}_{4}$ tetrahedra, which are connected by two $\mathrm{O}^{2-}$ anions. The apical oxygen atoms (O6) are directed to the same $(-c)$ pole of the crystal structure (Donnay and Buerger 1950; Barton 1969). The $T$ site is in majority occupied by $\mathrm{Si}$; it usually shows only a low degree of substitution. The most usual substituent is $\mathrm{Al}$ (Henry and Dutrow 1996), which in some cases can reach 0.85 apfu (Nishio-Hamane et al. 2014). The tetrahedron can also be occupied by B (e.g. Ertl et al. 2002a, 
2006, 2007, 2008, 2015; Hughes et al. 2004; Lussier et al. 2008, 2009; Kutzschbach et al. 2016, 2017).

The rings of tetrahedra are connected to two types of octahedra $-\mathrm{ZO}_{6}$ and $\mathrm{YO}_{6}$. The $\mathrm{ZO}_{6}$ octahedron is smaller than the $Y \mathrm{O}_{6}$ octahedron and is more distorted. It is connected to the $T(3 \times), Y(2 \times)$, and $B(2 \times)$ sites (Ertl et al. $2002 \mathrm{~b}$ ). As mentioned above, $\mathrm{ZO}_{6}$ octahedra form $3 \mathrm{D}$ framework (Bosi 2017).

The $Z$ site is dominantly occupied by trivalent cations, usually by $\mathrm{Al}$, but the end members of the tourmaline group including chromium-dravite, oxy-vanadiumdravite, oxy-chromium-dravite, vanadio-oxy-chromiumdravite, and povondraite have $\mathrm{Cr}^{3+}, \mathrm{V}^{3+}$, or $\mathrm{Fe}^{3+}$ as the dominant cation at the $Z$ site. In uvite, fluor-uvite, feruvite, povondraite and chromo-alumino-povondraite, oxy-dravite, and bosiite, the $Z$ site is occupied by $\mathrm{Mg}$ in addition to $\mathrm{Al}$ (Henry et al. 2011; Bosi and Skogby 2013; Ertl et al. 2016).

The $Y$ site is relatively regular octahedron larger in size than the $Z$ site. The $Y \mathrm{O}_{6}$ octahedron is connected by $\mathrm{O}$ atoms with $X(2 \times), T(2 \times), Z(3 \times)$, and $\mathrm{B}(2 \times)$ sites. The $Y$ site can accommodate a range of cation valences such as monovalent $\mathrm{Li}$, divalent $\mathrm{Fe}, \mathrm{Mg}, \mathrm{Mn}$, trivalent $\mathrm{Fe}, \mathrm{Al}$, $\mathrm{Cr}, \mathrm{V}$, and tetravalent Ti. Excess or decrease in charge can be balanced in neighbouring $Y$ sites $\left(\mathrm{Li}^{+}\right.$and $\left.\mathrm{Al}^{3+}\right)$ or in other cation or anion sites $\left(\mathrm{Al}^{3+}\right.$ in $T, \mathrm{Mg}$ in $Z, \mathrm{O}$ for $\mathrm{OH}$ in $V$ and $W$ ) (Foit and Rosenberg 1979).

The polyhedron around 9-coordinated $X$ site has a shape of a trigonal antiprism centred on the threefold symmetry axis (Henry and Dutrow 1996). The $X \mathrm{O}_{9}$ polyhedron is connected through $\mathrm{O}$ atoms to $T(6 \times), Y(3 \times)$, and $B(3 \times)$ sites. The $X$ site is usually occupied by $\mathrm{Na}$ and $\mathrm{Ca}$ but often can be vacant. According to the valence of cations present at the $X$ site, tourmalines can be divided into three groups: (1) alkali ( $\mathrm{Na}+\mathrm{K}$ are dominant), (2) calcic $(\mathrm{Ca})$ and (3) vacant (Hawthorne and Henry 1999; Henry et al. 2011).

Triangular $\mathrm{BO}_{3}$ groups are nearly perpendicular to $c$ and connect to the vertices of $\mathrm{ZO}_{6}$ and $\mathrm{YO}_{6}$ octahedra. The $\mathrm{BO}_{3}$ group shares $\mathrm{O}$ with $Z(2 \times), Y(2 \times)$, and $X$ $(3 \times)$ sites. Boron is the only cation entering the $B$ site. Although some presence of vacancies in the $B$ site was expected, no spectroscopic or structural studies found a clear evidence for the hypothesis (Grice and Ercit 1993; Hawthorne 1996).

\subsection{Anionic sites}

There are 31 anions in the structural formula of tourmaline. Anions present at the vertices of polyhedra are located at 8 sites, O1-O8. Oxygen occupies $\mathrm{O} 2$ and $\mathrm{O} 4-\mathrm{O} 8$ exclusively. The $\mathbf{O 2}$ site connects two $Y$ sites, $X$ and $B$ site. The $\mathbf{O 4}$ and $\mathrm{O5}$ sites connect two tetrahedra within $T_{6} \mathrm{O}_{18}$ rings. The $\mathbf{O 6}$ site links $Z$ and $Y$ sites to $T$ site, $\mathbf{O} 7$ site connects the $Z$ site with $T$ site. The $B$ site shares $\mathbf{O 8}$ with the $Z$ site.

One $\mathbf{O 1}(W)$ site and three $\mathbf{O 3}(V)$ sites can accommodate monovalent anions $\mathrm{OH}^{-}, \mathrm{F}^{-}$, or a divalent anion $\mathrm{O}^{2-}$ (Henry et al. 2011). The $W(\mathrm{O} 1)$ site is located on the threefold axis and represents the common vertex of three $\mathrm{YO}_{6}$ octahedra. Therefore, all $Y-\mathrm{O} 1$ bonds are crystallographically equivalent (Hawthorne 1996, 2002). From the bond-valence point of view, there are two different situations possible: 1) $W=\mathrm{OH}^{-}$or F- with bond valence c. $0.33 v u$; 2) $W=\mathrm{O}^{2-}$ - bond valence is $c .0 .67 v u$ ( $v u$ = valence units; Hawthorne 1996, 2002). The substitution of $\mathrm{O}$ for $\mathrm{OH}$ results in/from the increase of charge requirements in the neighbouring $Y$ sites and the substitution of $\mathrm{R}^{3+}$ for divalent cations.

The $V(\mathrm{O} 3)$ site is coordinated by one $Y$ and two $Z$ cations forming triangular pyramid, an arrangement similar to the $W$ position, but with a different bond valence among the $V$ and cations in octahedra (Hawthorne 1996, 2002). In most tourmalines, this site is occupied by an $\mathrm{OH}^{-}$anion with an exception of fluor-buergerite and (the hypothetical endmember) olenite with $\mathrm{O}^{2-}$. The presence of $\mathrm{O}^{2-}$ at this site increases negative charge, which is balanced by substitution of trivalent $\left(\mathrm{Fe}^{3+}, \mathrm{Al}^{3+}\right)$ for the divalent cations in the octahedral $Y$ site (Hawthorne 1996). Fluorine cannot occupy $V$ site for steric reasons (Hawthorne 2002).

\section{Bond length vs. occupancy dependency}

Published chemical composition and structural data were collected from American Mineralogist Crystal Structure Database (Downs and Hall-Wallace 2003) for tourmaline samples belonging to dravite-schorl, schorl-elbaite (including tsilaisites) and schorl ( \pm dravite $)-$ olenite series. These are divided according to their general composition and dominant substitution trends. Shortened names (schorl-dravite, elbaite, olenite and "buergerite" samples) are used. Consequently, schorl-elbaite series (shorter name - elbaite samples) includes not only elbaite but also Li-rich schorl, Mn-rich elbaite and tsilaisite. Olenite samples include Al-rich schorl, dravite and olenite. Note that some of "olenite" samples in the database have olenite formula (Al dominant at $Y$ site) only in disordered form, in ordered form these have dravite or oxy-dravite formulae. Full list of samples is in the supplementary material (Tab. S1).

Chemical composition was determined from electronmicroprobe data (EMPA) because its accuracy exceeds other analytical methods. Several compositions were determined, along with EMPA, also by Mössbauer spectroscopy and various techniques for $\mathrm{Li}-\mathrm{B}-\mathrm{H}$ measurement. Total cation contents unconstrained by $Y, Z$-disorder 


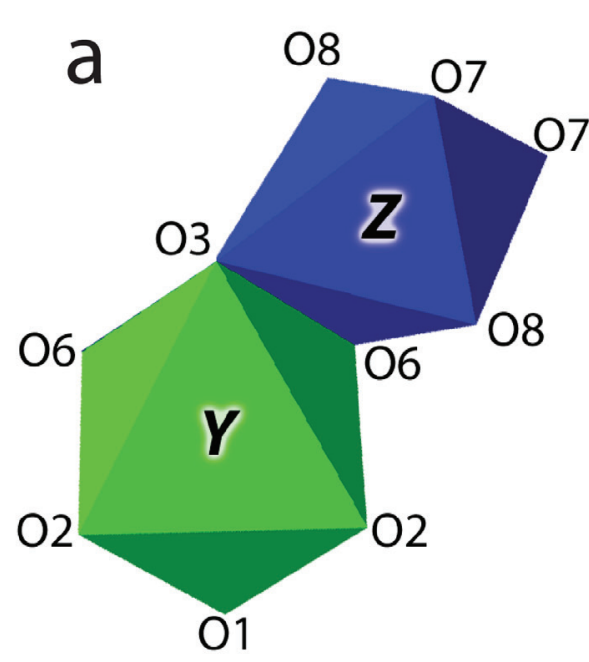

assignment, which may suffer subjective inconsistencies, were utilized. Structural information is focused on the all specific bond lengths at octahedral sites, not only on their average (Fig. 3), because the quality of the modern structural analyses is very high and errors in the specific sites locations and, consequently, bond lengths are very low. Cation contents and bond octahedral lengths were subjected to the correlation analysis.

\section{1. $\mathrm{YO}_{6}$ octahedron}

Bond-length and chemical composition analysis in $\mathrm{YO}_{6}$ octahedra revealed some intricate dependencies.

Total Fe displays positive correlations with all bond lengths except $Y-\mathrm{O} 2$ that is without a clear correlation or with a weak negative correlation in schorl-dravite series (Fig. $4 \mathrm{a}-\mathrm{d}$ ). In olenitic tourmalines, similar behaviour is observed but there is a positive trend indicated between $\mathrm{Fe}$ and $\mathrm{Y}-\mathrm{O} 2$. It is similar to elbaitic-tsilaisitic tourmalines, which, however, have weaker positive or even no clear correlations of Fe to other bond lengths. "Buergerite" samples are totally outside the general trend due to the dominance of $\mathrm{Fe}^{3+}$, which have a significantly smaller ionic radius than $\mathrm{Fe}^{2+}$.

In contrast, $\mathrm{Mg}$ displays negative trends with all bond lengths except with $Y-\mathrm{O} 2$, which shows a positive correlation in the schorl-dravite series (Fig. $4 \mathrm{e}-\mathrm{h}$ ). In other tourmalines, correlations are limited due to low $\mathrm{Mg}$ content. However, part of olenite samples are inside the schorl-dravite trend. Their composition expressed in ordered formula is mostly dravitic but they were described as olenite samples due to extensive Al-Mg disorder resulting in Al-dominance at the $Y$ site (Ertl et al. 2003; Bosi and Lucchesi 2004). However, there is no difference in bond-length and occupancy dependencies between these tourmalines and those described as dravite samples.
Fig. 3 Edge-shared $\mathrm{ZO}_{6}$ and $\mathrm{YO}_{6}$ octahedra in the polyhedron representation (a) and as a graph (b).

There is a difference between the schorl-dravite series and other tourmalines based on the $Y-\mathrm{O}$ bond-lengths and the total Al content (Fig. 5). Schorlitic and dravitic tourmalines and "buergerite" samples display a negative correlation only between $\mathrm{Al}$ and $\mathrm{O} 2$, which was described as result of bond-valence requirements in Al-rich tourmalines with preferential ${ }^{Z} \mathrm{Al}$ occupancy resulting in a weakened $Y-\mathrm{O} 6$ bond and consequent $Y-\mathrm{O} 2$ bond shortening (Bačík 2015). In contrast, Al-rich and Mg-poor olenite samples, elbaite samples and tsilaisites display a negative correlation of $\mathrm{Al}$ to all bond lengths. However, in case of $Y-\mathrm{O} 2$ and $\mathrm{Al}$, all tourmalines fall into one unique trend, which suggests that this is a general property of (at least) ${ }^{Y} \mathrm{Al}$-dominant tourmalines.

The Mn and Li content in schorl-dravite and "buergerite"-fluor-buergerite series is distinctly lower than in elbaitic and olenitic tourmalines, in most cases one or both cations were not analysed or listed in the chemical composition (Electronic Supplementary Material, Figs S1-2). Consequently, these tourmalines are missing in the above-mentioned correlation plots. Interestingly, Mn does not display any correlation with bond lengths except $Y-\mathrm{O} 6$, although $\mathrm{Mn}^{2+}$ has a larger ionic radius than $\mathrm{Al}^{3+}, \mathrm{Mg}^{2+}$ and $\mathrm{Li}^{+}$and similar to $\mathrm{Fe}^{2+}$. This different behaviour to chemically similar Fe likely results from its affinity to Li-bearing tourmalines, in which increased ${ }^{Y} \mathrm{Al}$ content has an opposite effect on expansion induced by the presence of ${ }^{Y} \mathrm{Mn}$. It is well documented by the negative correlations between $\mathrm{Li}$ and bond lengths in $\mathrm{YO}_{6}$ octahedra. However, there is a difference between olenite samples and elbaite-tsilaisite samples; olenite samples display larger reduction in bond lengths.

Fig. 4 Plot of total Fe vs. a $-Y-\mathrm{O} 1, \mathbf{b}-Y-\mathrm{O} 2$, c $-Y-\mathrm{O} 3$, d $-Y-\mathrm{O} 6$ bond lengths and total $\mathrm{Mg}$ vs. $\mathbf{e}-Y-\mathrm{O} 1, \mathbf{f}-Y-\mathrm{O} 2, \mathbf{g}-Y-\mathrm{O} 3, \mathbf{h}-Y-\mathrm{O} 6$ bond lengths. 

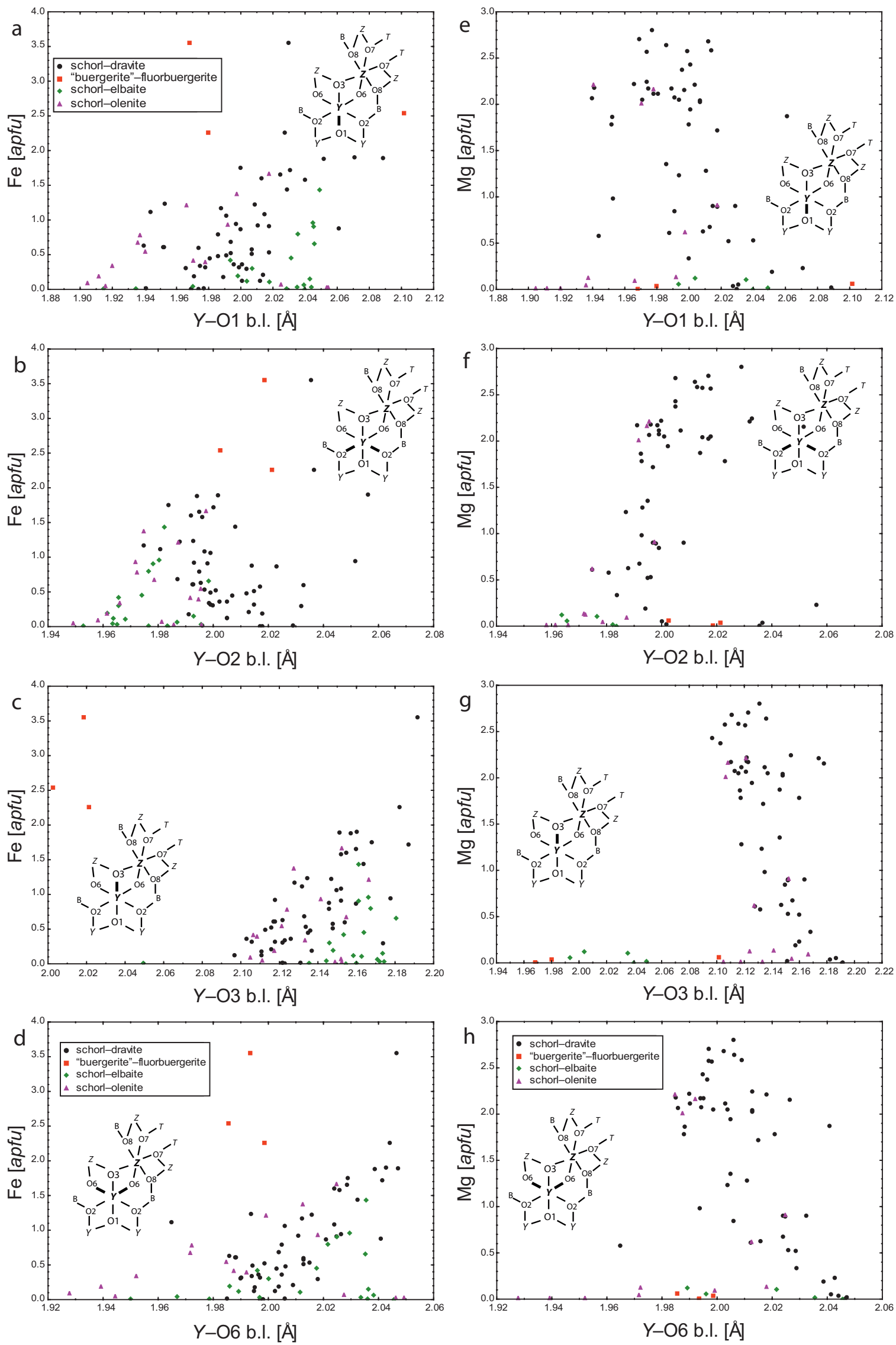

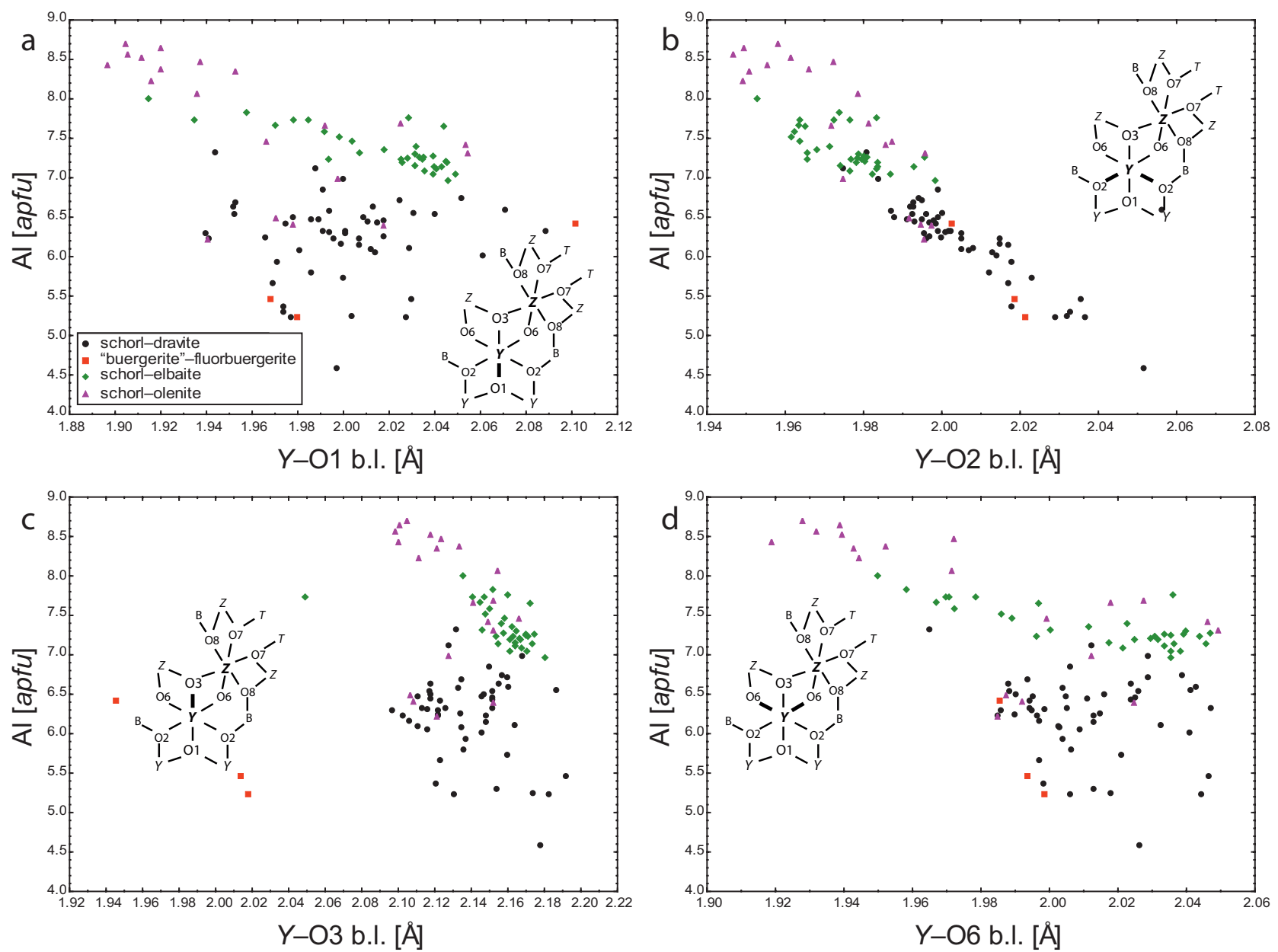

Fig. 5 Plot of total Al vs. a $-Y-\mathrm{O} 1, \mathbf{b}-Y-\mathrm{O} 2, \mathbf{c}-Y-\mathrm{O} 3, \mathbf{d}-Y-\mathrm{O} 6$ bond lengths.

By comparing $\mathrm{O} 1-Y-\mathrm{O} 3$ and $\mathrm{O} 2-Y-\mathrm{O} 6$ distances, which represent the dimensions of the whole $\mathrm{YO}_{6}$ octahedron, we can get a visualisation of octahedron geometry (Fig. 6). There are two distinct trends visible; the first

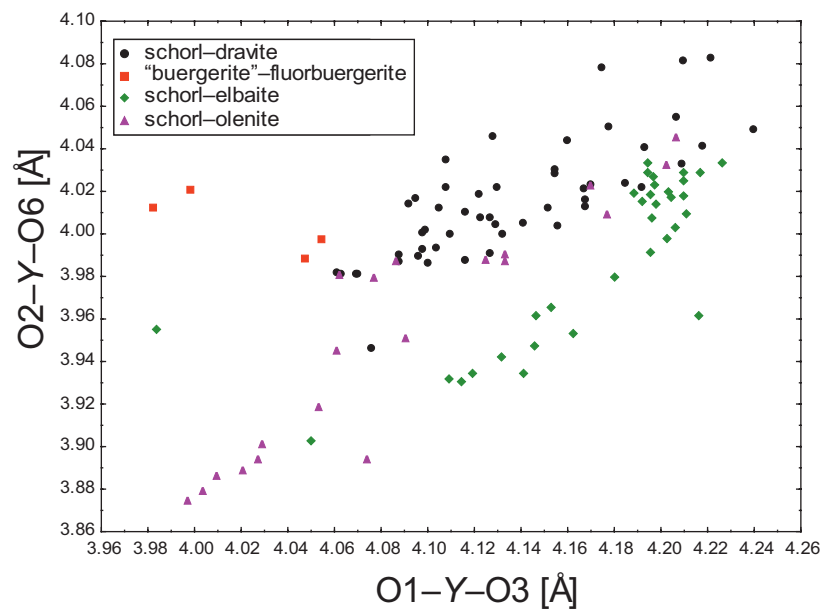

Fig. 6 Plot of $\mathrm{O} 1-Y-\mathrm{O} 3$ vs. $\mathrm{O} 2-Y-\mathrm{O} 6$ distances. includes schorl-dravite series and "buergerite" samples, the second elbaite and olenite samples. The latter trend displays larger reduction in $\mathrm{O} 2-Y-\mathrm{O} 6$, which suggests more pronounced expansion in $\mathrm{O} 1-Y-\mathrm{O} 3$ direction. This may result from an increase in $\mathrm{Al}^{3+}$, which, if oversaturated, occupies a larger proportion of $\mathrm{YO}_{6}$ octahedra in the formula unit. A compression due to stronger bonding is, therefore, more pronounced in $Y-\mathrm{O} 2$ and $Y-\mathrm{O} 6$ bonds .

\section{2. $\mathrm{ZO}_{6}$ octahedron}

Similar analysis in $\mathrm{ZO}_{6}$ octahedra also revealed differences between compositional types of tourmalines; olenite samples, elbaite samples and tsilaisites formed different trends compared to schorl samples and dravite samples. Moreover, differences were observed in the behaviour of selected cations.

The relationship between Fe content and bond lengths in the $\mathrm{ZO}_{6}$ octahedron is somehow ambiguous (Fig. 7). There are differences among schorl-dravite, elbaite, olenite and "buergerite" samples. The set of schorl to 

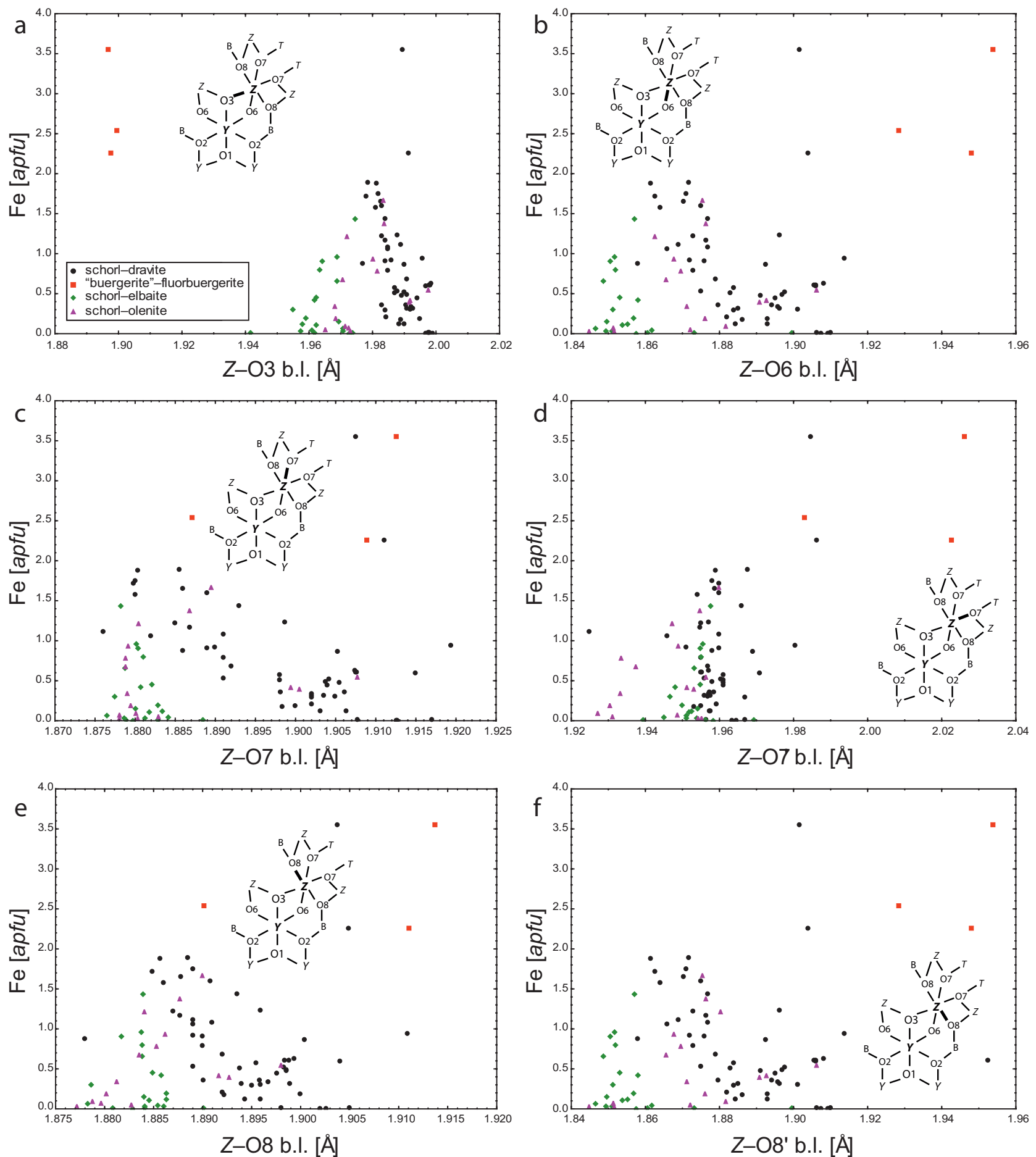

Fig. 7 Plot of total Fe vs. a $-Z-\mathrm{O} 3, \mathbf{b}-Z-\mathrm{O} 6, \mathbf{c}-Z-\mathrm{O} 7, \mathbf{d}-Z-\mathrm{O} 7$ ', e $-Z-\mathrm{O} 8, \mathbf{f}-Z-\mathrm{O} 8$ ' bond lengths.

dravite samples (updated from Bačík 2015) displays the same behaviour as already described - negative correlation to Z-O3, Z-O6, Z-07, Z-08 and Z-O8' bonds, no dependency on $Z-\mathrm{O} 7$ ' bond. These counterintuitive correlations suggest that $\mathrm{Fe}^{2+}$ with ionic radius larger than $\mathrm{Al}$ and $\mathrm{Mg}$ does not enter the $Z$ site in any significant proportion (Bačík 2015). Elbaite and olenite samples show no significant dependency of Fe on any bond length which also indicates the absence of $\mathrm{Fe}^{2+}$ at the $Z$ site. "Buergerite" samples are out of the general trend in most cases which can be attributed to the dominant $\mathrm{O}^{2-}$ at the O3 site. Moreover, "buergerite" samples display significantly larger $Z-07$ ', Z-O8 and Z-O8' bond lengths than other tourmalines suggesting possible presence of ${ }^{Z} \mathrm{Fe}^{3+}$. 

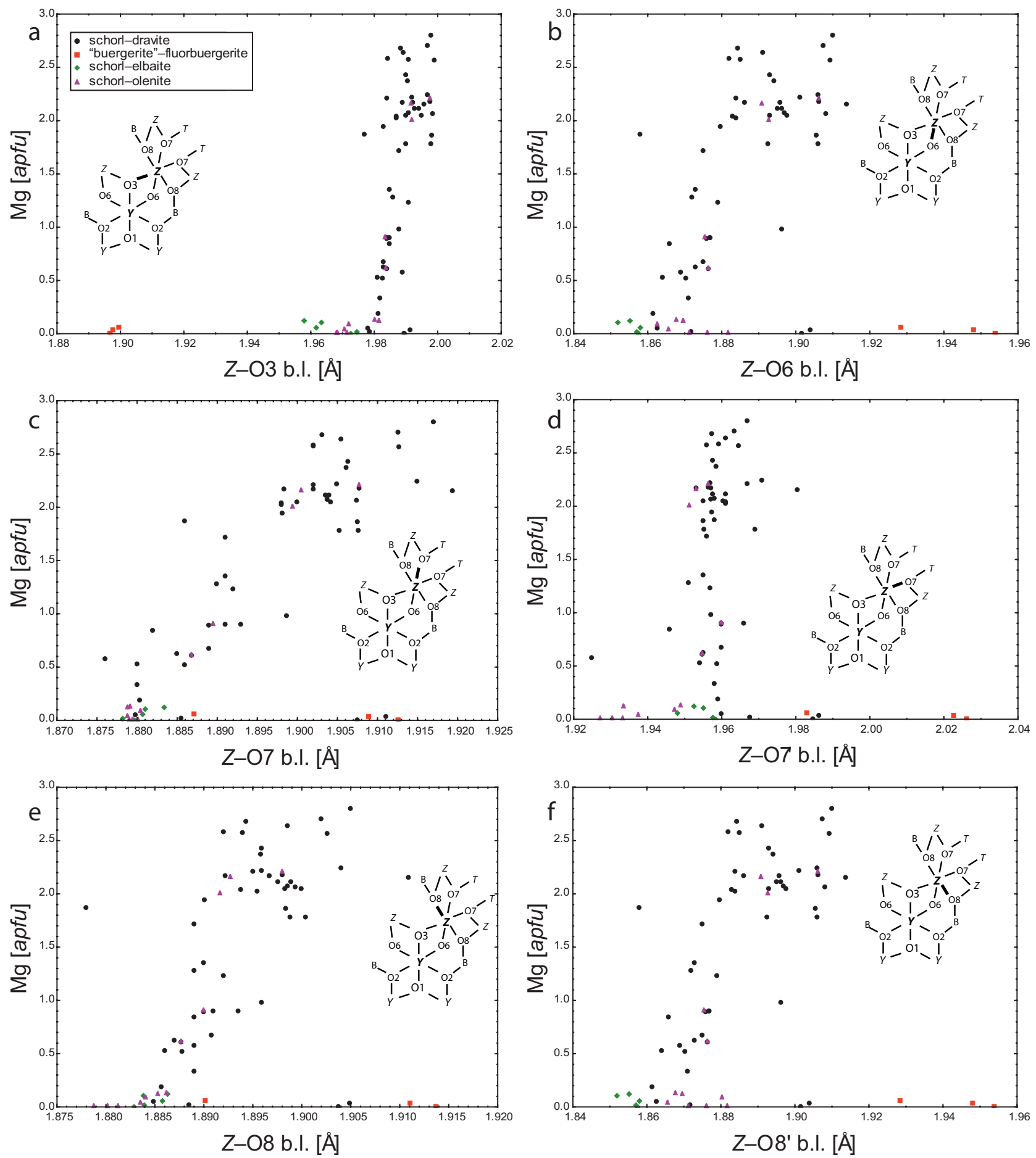

Fig. 8 Plot of total Mg vs. a $-Z-\mathrm{O} 3, \mathbf{b}-Z-\mathrm{O} 6, \mathbf{c}-Z-\mathrm{O} 7, \mathbf{d}-Z-\mathrm{O} 7$ ', e $-Z-\mathrm{O} 8, \mathbf{f}-Z-\mathrm{O} 8^{\prime}$ bond lengths.

A positive correlation of $\mathrm{Mg}$ and $Z-\mathrm{O}$ bond lengths documents partial presence of this element at the $Z$ site in all Mgbearing tourmalines (Fig. 8). It is also the only cation other than $\mathrm{Al}$, whose presence at the $Z$ site is indicated by this analysis. This supports previous observations (Bačík 2015).

The relations between $\mathrm{Al}$ and $\mathrm{Z}-\mathrm{O}$ bond lengths are the most interesting because this element is in abun- dance in all studied samples (Fig. 9). The $Z-\mathrm{O} 3$ bond length correlates negatively with $\mathrm{Al}$ in all tourmalines except "buergerite" samples, which deviate from the general trend due to ${ }^{V} \mathrm{O}$ dominance. This $\mathrm{Z}-\mathrm{O} 3$ shortening induces expansion of other bonds, which is the most pronounced in $\mathrm{Z}-\mathrm{O} 7$ ' and $\mathrm{Z}-\mathrm{O}$ 8' $^{\prime}$ bonds. In other tourmalines, there is one general trend of the negative 

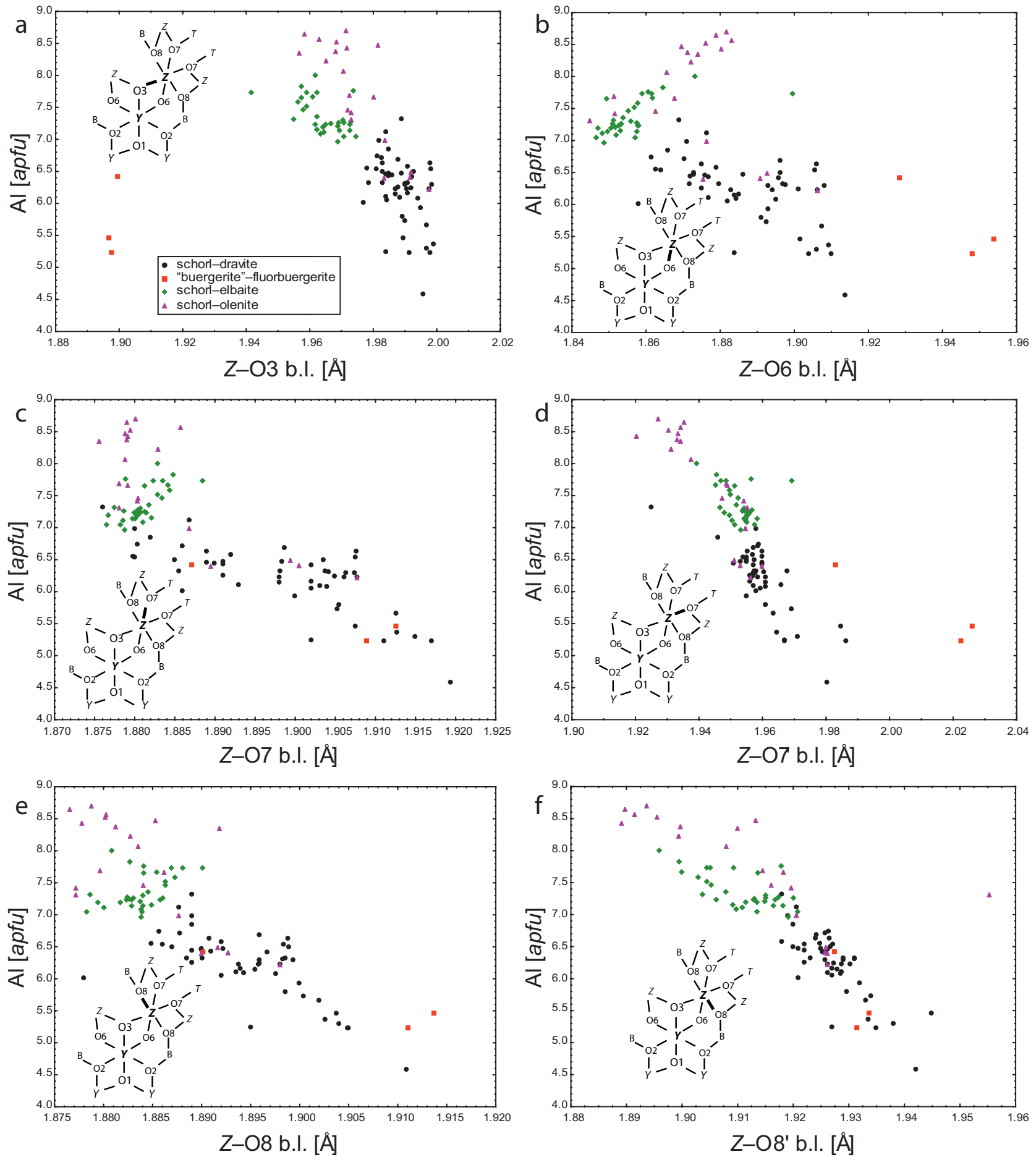

Fig. 9 Plot of total Al vs. a - Z-O3, b-Z-O6, c - Z-O7, d - Z-O7', e - Z-O8, f $-Z-\mathrm{O} 8$ ' bond lengths.

correlation between $\mathrm{Al}$ and $\mathrm{Z}-\mathrm{O} 3, \mathrm{Z}-\mathrm{O} 7, \mathrm{Z}-\mathrm{O} 7,, \mathrm{Z}-\mathrm{O} 8$ and $Z-08$ '. There is, however, difference in dependency of Al and Z-O6 bond length between schorl and dravite samples on the one side and elbaite, tsilaisites and olenite samples on the other side. The first group displays a negative correlation, while the second correlates positively. A negative correlation in tourmalines with lower $\mathrm{Al}$ can be explained by the presence of ${ }^{\mathrm{Z}} \mathrm{Mg}$ substituting for ${ }^{Z} \mathrm{Al}$; with decreasing ${ }^{Z} \mathrm{Mg}$ and increasing ${ }^{z} \mathrm{Al}$, the bond length shortens. However, due to the low $\mathrm{Mg}$ content and no other possible elements substituting for $\mathrm{Al}$, this mechanism cannot be applied to explain positive correlation in Al-rich tourmalines. This requires further analysis of bond valence. 

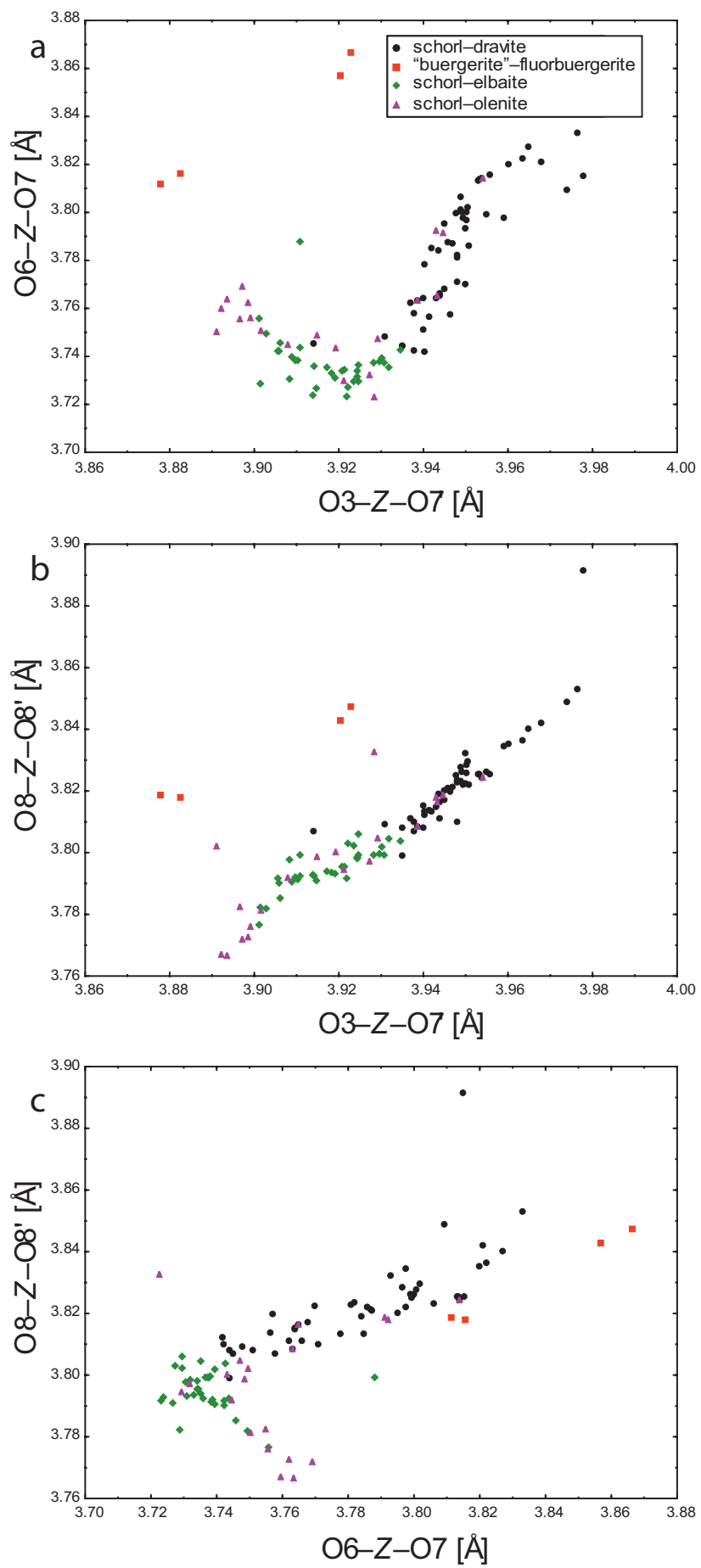

Fig. 10 Plot of $\mathbf{a}-\mathrm{O} 3-Z-\mathrm{O} 7$ ' vs. O6-Z-O7, b-O3-Z-O7'vs. O8-ZO8', c- O6-Z-O7 vs. O8-Z-O8' distances.

In contrast, $\mathrm{Mn}$ and Li display no significant correlations and only small variability in bond lengths (Figs S34). It suggests that the $Z$ site of $\mathrm{Mn}$ - and Li-rich tourmalines is almost completely occupied by $\mathrm{Al}$ and variations in bond lengths result from either the small proportion of ${ }^{\mathrm{z}} \mathrm{Mg}$ (Mg-rich olenite samples) or variable occupancy of neighbouring sites, mainly $Y$ site with $\mathrm{Al}, \mathrm{Mn}$ and $\mathrm{Li}$.
A comparison of O3-Z-O7', O6-Z-O7 and O8-Z-O8' distances allows us to visualize the $Z_{6}$ octahedron geometry (Fig. 10). We can see linear dependency of $\mathrm{O} 3-Z-\mathrm{O} 7$ ' and $\mathrm{O} 8-Z-\mathrm{O} 8$ ' in all samples suggesting linear contraction of the octahedron in these directions presumably due to an increase in ${ }^{z} \mathrm{Al}$. "Buergerite" samples are out of the trend which is influenced, as already mentioned, by ${ }^{V} \mathrm{O}$. However, $\mathrm{O} 6-Z-\mathrm{O} 7$ forms "smoking pipe" trend with $\mathrm{O} 3-Z-\mathrm{O} 7$ ' and similarly strange behaviour, if compared to O8-Z-O8'. Both figures (Fig. 10a, c) suggest that contraction of octahedron in the O6-Z-O7 direction changes to expansion, although the contraction continues in the other two directions. This can be explained by the bond-valence analysis.

\section{Bond valence estimation}

Bond valence can be calculated using the following equation (Brown 2002):

$$
v_{i j}=\exp \left(\left(R_{0}-d_{i j}\right) / b\right)
$$

where: the bond valence $v_{i j}$ is a measure of the bond valence between two given atoms at the distance of $d_{i j}$ (= bond length), $R_{0}$ is the length of a single bond (for which $\left.v_{i j}=1\right)$ and $b$ is a universal parameter with a typical value of $0.37 \AA$. Default values of $R_{0}$ and $b$ parameters for were taken from Gagné and Hawthorne (2015) and Bond valence parameters file version 2013 (Brown 2013).

For complex system of octahedral sites such as in tourmaline, it is too complicated, or even impossible, to determine the exact bond valences, if the exact site occupancy is not considered. The reason for this complexity is that the bond length measured from structural refinement (SREF) is the average value for many different arrangements with variable occupancy. In selected mineral series, we can use values for $\mathrm{Al}-\mathrm{O}$ bond as a dominant type in the $\mathrm{ZO}_{6}$ octahedron. These resulting values are, however, only approximate and used only to interpret the bond-length variations at the $Z$ site. In case of $Y$ site, the occupancy is too diverse to reveal any meaningful values and therefore, will not be examined here.

Calculated bond valences for each bond were compared to the total $\mathrm{Al}$ content. As expected, the trends are reverse to those from bond length to $\mathrm{Al}$ comparison. The $Z$ site has a positive correlation of all bonds to $\mathrm{Al}$, except $Z-06$ which displays a negative correlation (decrease in bond valence) in olenite samples.

In addition, this calculation provides approximate values of bond valence which can be studied in further detail. Ideal bond valences for all studied bonds (Tab. 1) can be used for interpretation of general trends. Bonds in the $\mathrm{ZO}_{6}$ octahedron can be divided into several groups according to bond valence values (Fig. S6): 
Tab. 1 Ideal bond lengths for selected cation-oxygen bonds in octahedral coordination calculated for empirical bond-valence parameter values by Brown (2013) and Gagné and Hawthorne (2015)

\begin{tabular}{lcc}
\hline Bond & Bond valence $[v u]$ & Bond length $[\AA]$ \\
\hline $\mathrm{Al}-\mathrm{O}$ & 0.50 & 1.904 \\
$\mathrm{Fe}^{2+}-\mathrm{O}$ & 0.33 & 2.1536 \\
$\mathrm{Mg}-\mathrm{O}$ & 0.33 & 2.0991 \\
$\mathrm{Mn}^{2+}-\mathrm{O}$ & 0.33 & 2.2023 \\
$\mathrm{Li}-\mathrm{O}$ & 0.17 & 2.1996 \\
$\mathrm{Fe}^{2+}-\mathrm{F}$ & 0.33 & 2.0602 \\
$\mathrm{Fe}^{3+}-\mathrm{F}$ & 0.50 & 1.9355 \\
\hline
\end{tabular}

(a) Z-O3 - most tourmalines have bond valence between 0.36 and $0.40 v u$. This is consistent with values calculated for ${ }^{Y} \mathrm{Mg}+2{ }^{\mathrm{Z}} \mathrm{Al}+{ }^{\mathrm{O} 3} \mathrm{OH}$ arrangement $-0.23 v u$ $+2 \times 0.46 v u$ (Hawthorne 2002) as in the case of the $Y-\mathrm{O}$ bond. Similarly, the bond valence in "buergerite" samples increases to $0.47 v u$. There is a relatively well-correlated increase in bond valence from schorl and dravite samples to elbaite and olenite samples.

(b) Z-O6 - "buergerite" samples have distinctly lower bond valence $(0.40-0.43 v u)$ which compensates the high valence of the $Z-\mathrm{O} 3$ bond. It increases in schorl and dravite samples from 0.45 to $0.52 v u$. The highest bond valence is observed in elbaite samples (0.52-0.54 $v u$ ) but it decreases again in olenite samples to $0.50 \mathrm{vu}$. $\mathrm{O} 6$ is shared edge of the both $\mathrm{YO}_{6}$ and $\mathrm{ZO}_{6}$ octahedra. Therefore, if one considers the relatively rapid increase in $Y-06$ bond valence due to enrichment in $\mathrm{Al}^{3+}$ at $Y$, it cannot be effectively compensated by the $T-\mathrm{O} 6$ bond, although substitution of $\mathrm{Al}^{3+}$ for $\mathrm{Si}^{4+}$ can balance it partly. Consequently, $\mathrm{Z}-\mathrm{O} 6$ and $\mathrm{Y}-\mathrm{O} 6$ bonds influence each other and balance bond valence variations.

(c) Z-O7' - this bond has a different behaviour to $Z-\mathrm{O} 7$ because it is the counterpart of $Z-\mathrm{O} 3$ bond in the octahedron and furthermore, in two $\mathrm{ZO}_{6}$ octahedra joint by $\mathrm{O} 3$ site, two $\mathrm{O} 3-\mathrm{Z}-\mathrm{O} 7$ ' body diagonals are interconnected in almost straight line (bending only due to bond angles different than $90^{\circ}$ ). Therefore, the $Z-\mathrm{O} 7^{\prime}$ ' bond reflects the variations at $\mathrm{O} 3$ site. "Buergerite" samples have lower bond valence $(0.34 v u)$ than other tourmalines again. It results from the presence of $\mathrm{O}^{2-}$ at $\mathrm{O} 3$ which induces higher bond valence and attractive force on the cation at $Z$. This prolongs and weakens the $Z-07$ ' bond. In other tourmalines, the bond valence increases from 0.39 to 0.44 $v u$ which is consistent with the increase in ${ }^{Z} \mathrm{Al}$ content.

(d) Z-O7, Z-O8 and Z-O8' - these bonds display similar trend of linear increase in bond valence from 0.45 to $0.50 v u$. It needs to be mentioned that $0.50 v u$ is the bond valence of $\mathrm{Al}-\mathrm{O}$ bond in the ideal octahedron (Tab. 1). It is supported by the upper limit of $Z-07$ and $Z-\mathrm{O} 8$ bond valence at $0.50 v u$. The $\mathrm{O} 7$ and $\mathrm{O} 8$ sites are shared between two $Z$ sites and $\mathrm{B}(\mathrm{O} 7)$ and $T$ site $(\mathrm{O} 8)$. Cations in these sites have relatively high valence $\left(\mathrm{Si}^{4+}\right.$, $\mathrm{Al}^{3+}, \mathrm{B}^{3+}$ ) and a low coordination number (3-6), therefore, their bonds are stronger and less variable. Consequently, the bond valence of Z-O7, Z-O8 and Z-O8' at full ${ }^{Z} \mathrm{Al}^{3+}$ occupancy tends to approach an ideal value of $0.50 \mathrm{vu}$.

If the sum of bond valences in the $\mathrm{ZO}_{6}$ octahedron is calculated, general trends can be observed (Fig. 11). The bond valence sum increases monotonously from $2.5 v u$ in Al-poor tourmalines to $2.8 v u$ in elbaite and olenite samples. In Al-poor tourmalines, there is usually a proportion of $\mathrm{Mg}$ at the $\mathrm{Z}$ site present due to $\mathrm{Al}-\mathrm{Mg}$ disorder (Grice and Ercit 1993; Hawthorne et al. 1993; Bloodaxe et al. 1999; Bosi and Lucchesi 2004; Marschall et al. 2004; Ertl et al. 2010). Such a bond-valence sum brings relatively clear evidence of this disorder, although the sum would get higher, if disorder is considered and $\mathrm{Mg}-\mathrm{O}$ values would be used. Consequently, the real proportion of ${ }^{Z} \mathrm{Mg}$ surely is not half of the site occupancy as suggested by the values near $2.5 \mathrm{vu}$. The bond valence sum does not increase further than around $2.8 v u$ in elbaite and olenite samples which is the upper limit for the $Z\left[\mathrm{O}_{5}(\mathrm{OH})\right]$ octahedron. In these tourmalines, it can be supposed with confidence that the Al occupancy of the $Z$ site is close to $100 \%$.

\section{Octahedral metrics}

For determination of the overall octahedral geometry, the most frequent distortion parameters used in mineralogy and crystallography are: 1) quadratic elongation (Robinson et al. 1970) and volume distortion (Makovicky and Balic-Zunic 1998), which give a measure of the global distortion of an octahedron; 2) bond-length distortion (Brown and Shannon 1973), which contributes to vary the global distortion; 3) bond-angle variance (Robinson et al. 1970), which is a measure of angular distortion with respect to a regular octahedron and also contributes to the global distortion.

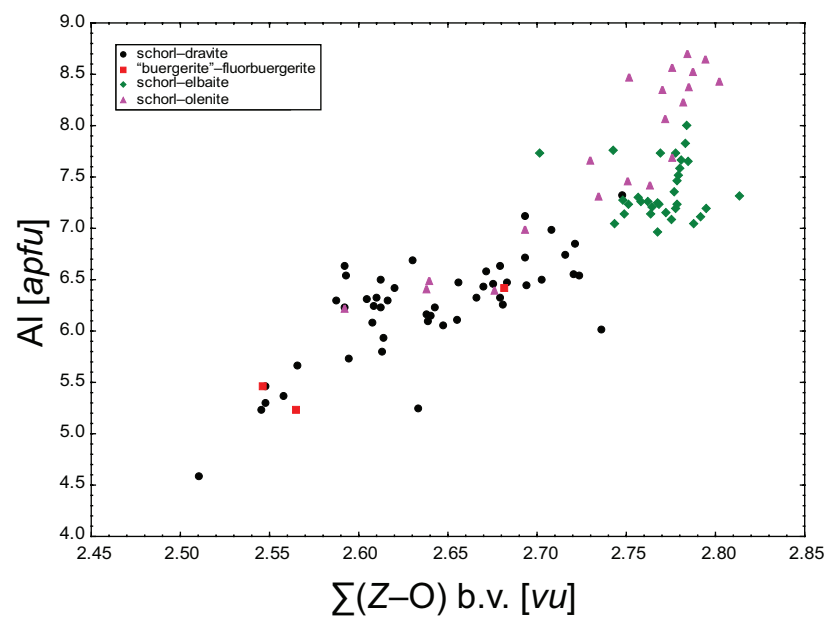

Fig. 11 Plot of total $\mathrm{Al}$ vs. bond valences sum in the $\mathrm{ZO}_{6}$ octahedra. 
If individual bond lengths are considered, the octahedral geometry can be expressed by the octahedral metrics and the deviation from the ideal octahedron. Considering $\mathrm{O}^{2-}$ ionic radius (1.36 $\AA$ in 3 -fold and 1.38 in 4-fold coordination, Shannon 1976), the R-O bond length is equal to $1.92 \AA$. By subtracting the $\mathrm{O}^{2-}$ ionic radius, we get a central-cation ionic radius of $0.54-0.56 \AA$. The ionic radius of $\mathrm{Al}^{3+}$ in octahedral coordination is equal to $0.535 \AA$ (Shannon 1976). It is very close to the ideal value; consequently, isolated $\mathrm{Al}^{3+}$-bearing octahedron should not be subjected to any bond-length distortion in the rigid-sphere model. If any distortion occurs in real structures, it should be attributed to the influence of surrounding polyhedra.

However, the ideal $\mathrm{Al}-\mathrm{O}$ bond length for octahedral coordination calculated using bond-valence approach (Brown 2002) is slightly shorter - $1.9043 \AA$. This indicates that attractive electrostatic force of $\mathrm{Al}^{3+}$ results in larger shortening of $\mathrm{Al}-\mathrm{O}$ bonds compared to the idealoctahedron model with bond-length determined by (cation + anion) ionic radii. This can explain decrease of the average bond lengths of the $\mathrm{ZO}_{6}$ octahedron of all studied tourmalines, where the $\langle Z-\mathrm{O}\rangle$ distance is below 1.92 $\AA$ (Tab. S2). This is the case for both $Z-\mathrm{O} 7$ and $Z-\mathrm{O} 8$ bonds. Both $Z-\mathrm{O} 3$ and $Z-\mathrm{O} 7$ ' bonds are longer. The $Z-\mathrm{O} 3$ bond length is expanded due to $\mathrm{OH}$ group dominance at $\mathrm{O} 3$ site which also causes the elongation of $\mathrm{Z}-\mathrm{O} 7$ ' bond. The $\mathrm{O}-\mathrm{H}$ bond valence, which is slightly lower than $1 \mathrm{vu}$ due to hydrogen bond, reduces in the $Z-\mathrm{O} 3$ bond valence to $0.36 v u$ (Fig. S5a).

However, the Z-O6 bond length in the most Al-rich tourmalines is distinctly lower than $1.8765 \AA$, calculated for the ideal Al-O bond. The straightforward explanation results from the comparison of each bond valence. It exceeds $0.50 v u$ in elbaite samples and in part of olenite samples where it balances the bond-valences in a very complicated relationship between $\mathrm{YO}_{6}$ and $\mathrm{ZO}_{6}$ octahedra. This suggests that the usually used rigid-sphere model is insufficient, not only in the case of the Jahn-Teller distortion (e.g. Goodenough 1964; Burns and Strens 1967; Faye 1968; Ito and Hafner 1974; Burns and Hawthorne 1996; Kyono et al. 2012; Bačík et al. 2014; Ertl et al. 2015; Fridrichová et al. 2017), but short-range bond-valence effects also influence the geometry of ions and coordination bodies in the interaction between "spherical" ions.

\subsection{Octahedral bond-length metrics}

The bond-length distortion can be calculated as $\Delta_{\text {oct }}=$ $1 / 6 \sum\left[\left(d_{\mathrm{i}}-d_{\mathrm{m}}\right) / d_{\mathrm{m}}\right]^{2}$, where $d_{\mathrm{i}}$ is each individual $Y-\mathrm{O}$ or $Z-\mathrm{O}$ bond length and $d_{\mathrm{m}}$ is $\langle Y-\mathrm{O}\rangle$ or $\langle Z-\mathrm{O}\rangle$ (average) bond length (Ertl et al. 2002b). However, the shape of octahedral and its divergence from the ideal metrics can be also expressed as the ratio of two opposite bond lengths sums, which approximates for the octahedral space diagonals. The $\mathrm{YO}_{6}$ octahedron has a monoclinic $m$ symmetry and is prolonged in the $\mathrm{O} 1-Y-\mathrm{O} 3$ direction due to the dominant $\mathrm{OH}$ occupancy of both $\mathrm{O} 1$ and $\mathrm{O} 3$ sites in most tourmalines. Because both $Y-\mathrm{O} 2$ and similarly both $Y-\mathrm{O} 6$ bonds are related to each other by the mirror plane, both $\mathrm{O} 2-Y-\mathrm{O} 6$ distances are equal. Only "buergerite" samples display a shortening in $\mathrm{O} 1-Y-\mathrm{O} 3$ direction, which produces an almost regular, only slightly flattened $\mathrm{YO}_{6}$ octahedron.

The $\mathrm{ZO}_{6}$ octahedron is also prolonged in the $\mathrm{O} 3-\mathrm{Y}-\mathrm{O} 7$ direction due to the dominant $\mathrm{OH}$ occupancy at the $\mathrm{O} 3$ site in most tourmalines. However, it has lower symmetry because none of the bonds is related to any other by any symmetry operation. Consequently, the $Z_{6} \mathrm{O}_{6}$ octahedron has triclinic metrics with $\mathrm{O} 3-Y-\mathrm{O} 7>0$ O $-Z-\mathrm{O} 8$ ' $>06-Z-07$. The reasons for variations in each of the octahedron metrics will be discussed in detail in sections 5.2 and 5.3.

\subsection{Metrics of the $\mathrm{YO}_{6}$ octahedron}

Variations in bond and angular distortions in the $\mathrm{YO}_{6}$ octahedron are larger than in the $\mathrm{ZO}_{6}$ octahedron. Such distortions are influenced by both the occupying cation size and the neighbouring polyhedra. However, the effects of individual factors are difficult to separate (Ertl et al. 2002b). The cation influence on the octahedral angular distortion decreases from $\mathrm{Li}-\mathrm{Al}$ tourmalines with the largest distortion to $\mathrm{Mg}$ tourmalines (dravite, uvite) with the smallest distortion. Therefore, the smallest $\mathrm{Ti}^{4+}$ and $\mathrm{Al}^{3+}$ cations produce the highest distortion (Ertl et al. 2002b).

The largest octahedral distortion $\left(\Delta_{\text {oct }}\right)$ was observed in Al-rich tourmalines elbaite and olenite (Ertl et al. 2002b). In the studied set, such tourmalines display a relatively uniform negative correlation of $\mathrm{Al}$ to all bond lengths in $\mathrm{YO}_{6}$ octahedron (Fig. 5). The octahedral metrics ratio, calculated as $\mathrm{O} 1-Y-\mathrm{O} 3 / \mathrm{O} 2-Y-\mathrm{O} 6$, is also the largest in elbaite samples - more than 1.05 (Fig. 12). Manganese displays no correlation to any bond length, except $Y-\mathrm{O} 6$. Lithium shows a negative correlation to each bond length, although the $\mathrm{Li}-\mathrm{O}$ bond length is similar to $\mathrm{Mg}-\mathrm{O}$ and $\mathrm{Fe}^{2+}-\mathrm{O}$ (Tab. 1). Such a negative correlation is present in elbaite and olenite, although the trend is different in these tourmalines. This suggests that in this case, the degree of the octahedral distortion is a function of the $\mathrm{Al}$ content.

"Buergerite" samples (fluor-buergerite, buergerite) display the lowest $\mathrm{O} 1-Y-\mathrm{O} 3 / \mathrm{O} 2-Y-\mathrm{O} 6$ ratio of $0.99-1.01$. Consequently, the $\mathrm{YO}_{6}$ octahedron is relatively regular in such tourmalines. However, there is a difference between (natural) fluor-buergerite samples (Tippe and Hamilton 1971; Grice and Ercit 1993) and buergerite produced 
from schorl by the heat treatment (Ertl et al. 2012). Fluorbuergerite has a relatively long $Y-\mathrm{O} 1$ bond $-c .2 .10 \AA$, while $Y-\mathrm{O} 3$ is significantly shortened (c. $1.95 \AA$ - Tippe and Hamilton 1971). The shortening can be attributed to the dominant occupancy of $\mathrm{O} 3$ site by $\mathrm{O}^{2-}$. Interestingly, the observed $Y-\mathrm{O} 1$ bond length does not approach the ideal $\mathrm{Fe}^{3+}-\mathrm{F}$ bond length of $1.9355 \AA$. The ideal $\mathrm{Fe}^{2+}-\mathrm{F}$ bond length is closer to the measured values $-2.0602 \AA$. The most likely explanation is that $Y-\mathrm{O} 1$ bond length is the average of $\mathrm{Fe}^{3+}-\mathrm{F}, \mathrm{Fe}^{2+}-\mathrm{F}$, and $\mathrm{Fe}^{2+}-\mathrm{OH}$ bond lengths (possibly with additions of other cations). Nevertheless, nothing indicates that $\mathrm{O}^{2-}$ is present at $\mathrm{O} 1$ in any significant amount. In contrast, synthetic buergerite displays significant shortening of both $Y-\mathrm{O} 1$ and $Y-\mathrm{O} 3$ bond lengths. This suggests a relatively homogeneous deprotonation of the $\mathrm{OH}$ sites by heat treatment. Interestingly, the sum of $Y-\mathrm{O} 1$ and $Y-\mathrm{O} 3$ bond lengths in both types of "buergerite" samples is very similar. This suggests that a deprotonation at the $\mathrm{O} 3( \pm \mathrm{O} 1)$ site results in a smaller irregularity of the $\mathrm{YO}_{6}$ octahedron.

A reduced $\mathrm{YO}_{6}$ octahedral irregularity can also be observed in tourmalines of the schorl-dravite series. This is consistent with a very small $\Delta_{\text {oct }}$ in dravite (Ertl et al. 2002b). The $\mathrm{O} 1-Y-\mathrm{O} 3 / \mathrm{O} 2-Y-\mathrm{Oct}$ ratio is highly negatively correlated with the $\mathrm{Mg}$ content. Magnesium reduces the octahedral irregularity because it is usually distributed among both $Y$ and $Z$ sites. Therefore, although it significantly shortens the $Y-\mathrm{O} 3$ and $Y-\mathrm{O} 6$ bond lengths (Fig. $4 \mathrm{~g}-\mathrm{h}$ ), the presence of ${ }^{\mathrm{Z}} \mathrm{Mg}$ results in elongation of $Y-\mathrm{O} 2$ bond (Fig. 4f). This effect is typical of Mg-rich tourmalines in which simultaneous weakening of $\mathrm{Z}-\mathrm{O} 3$ and $\mathrm{Z}-\mathrm{O} 6$ bonds due to ${ }^{\mathrm{Z}} \mathrm{Mg}$ presence results in a valence increase and a reducing of the $Y-\mathrm{O} 6$ bond. This, moreover, induces a $Y-\mathrm{O} 2$ bond expansion (Bačík 2015).

In contrast, $\mathrm{Fe}$ induces larger $Y_{6}$ octahedral bondlength variations in tourmalines of the schorl-dravite series; very Fe-rich schorl samples have an irregularity similar to elbaite with a $\mathrm{O} 1-Y-\mathrm{O} 3 / \mathrm{O} 2-Y-\mathrm{O} 6$ ratio of almost 1.05. The $Y$ site of these tourmalines is relatively strongly distorted octahedron prolonged in the $\mathrm{O} 1-Y_{-}$ $\mathrm{O} 3$ direction. This geometry is typical of $\mathrm{Fe}^{2+}$-bearing Jahn-Teller distorted octahedra, which was also observed, e.g., in spinels, chlorites, micas, and gadolinitesupergroup minerals (Goodenough 1964; Faye 1968; Ito and Hafner 1974; Kyono et al. 2012; Bačík et al. 2014). Ferrous iron in the octahedral ligand field has the highspin $[\mathrm{Ar}] 3 d^{4}:\left(\mathrm{t}_{2 \mathrm{~g}}\right)^{4}\left(\mathrm{e}_{\mathrm{g}}\right)^{2}$ electronic configuration, which is degenerated and according to Jahn-Teller's theory (Jahn and Teller 1937), it leads to distortion to remove the degeneracy and spontaneously reduces its symmetry (Burns 2005). The $\mathrm{YO}_{6}$ octahedron with two weaker opposite ligands is an ideal environment for the $\mathrm{Fe}^{2+}$ cation which can also choose energetically lower and
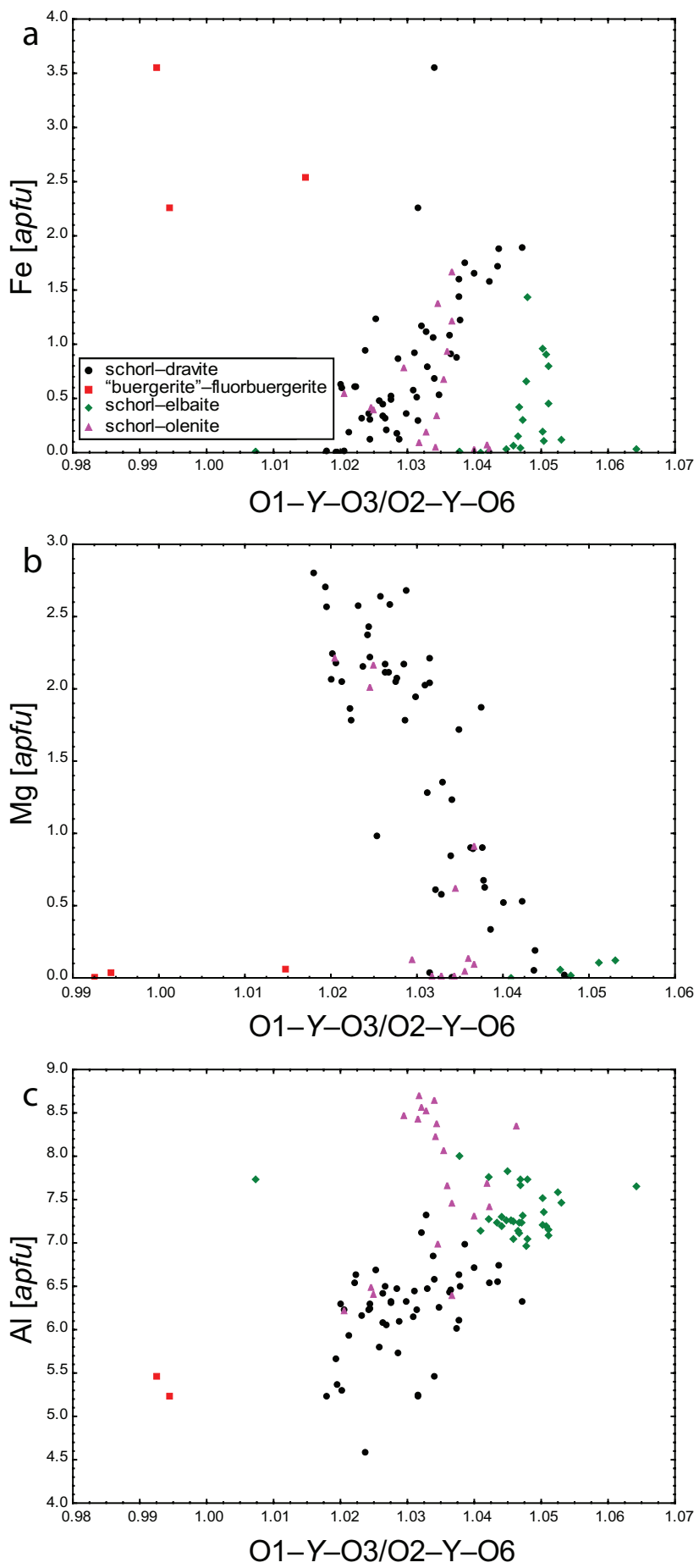

Fig. 12 Plot of $\mathrm{O} 1-Y-\mathrm{O} 3 / \mathrm{O} 2-Y-\mathrm{O} 6$ ratio vs. a $-\mathrm{Fe} ; \mathbf{b}-\mathrm{Mg}, \mathbf{c}-\mathrm{A}$.

more stable $\left(\mathrm{t}_{2 \mathrm{~g}}\right)^{4}\left(\mathrm{e}_{\mathrm{g}}\right)^{2}$ configuration with two $d$ electrons in axial orbitals. Consequently, it is possible that the Jahn-Teller distortion of a $\mathrm{Fe}^{2+}$-bearing $\mathrm{YO}_{6}$ octahedron is just a normal feature of a $\mathrm{Fe}^{2+}$-bearing tourmaline. Furthermore, it could be one of the important factors for $\mathrm{Fe}^{2+}$ to preferentially occupy the $Y$ site instead of the $Z$ site, which is not only smaller, but also more (triclinically) distorted than the $Y$ site. 

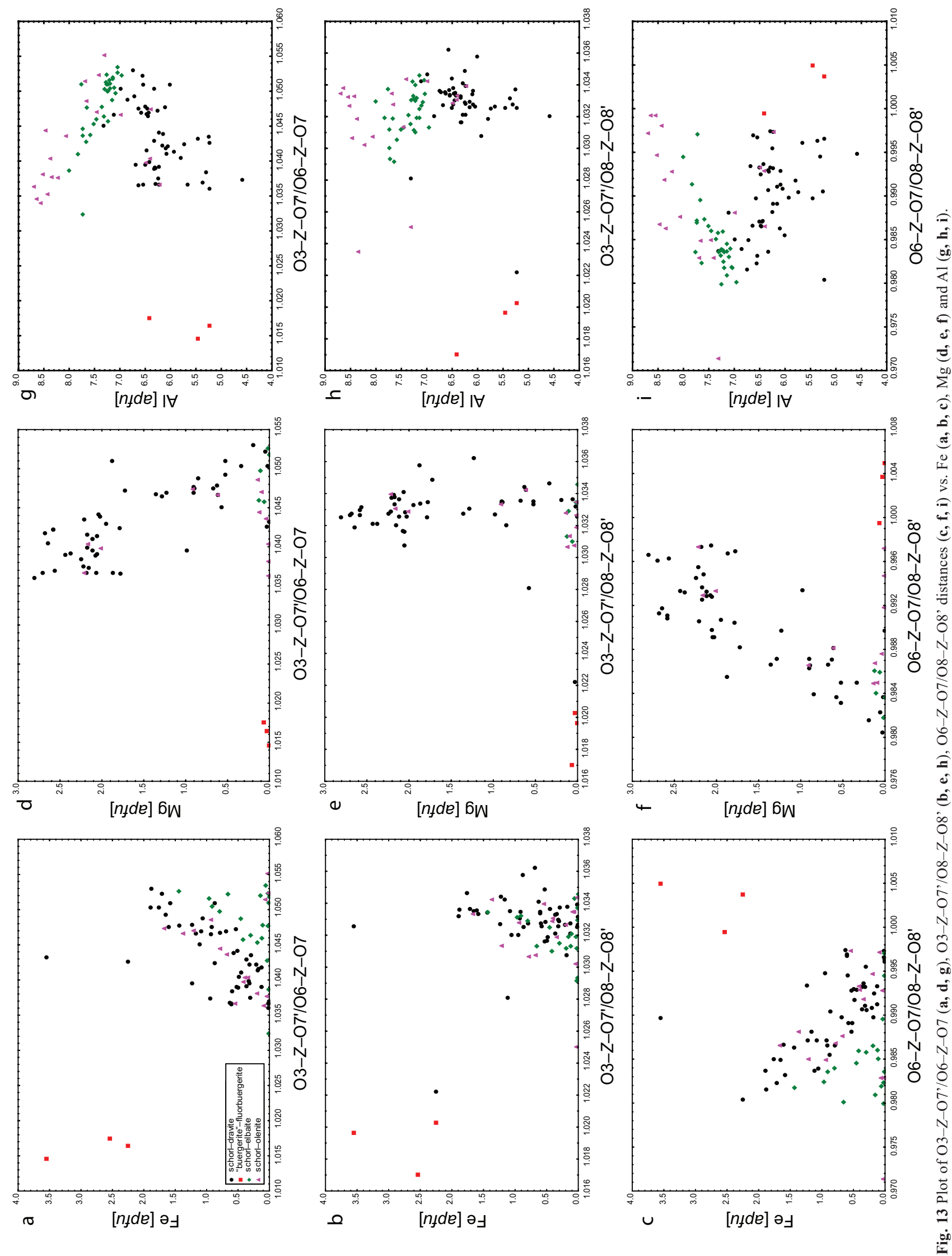


\subsection{Metrics of the $\mathrm{ZO}_{6}$ octahedron}

There is a very high negative correlation between bond-angle distortion of the $\mathrm{ZO}_{6}$ octahedron and $<Y-$ $\mathrm{O}>$ bond length for all tourmalines where $\mathrm{O} 3$ site is occupied by OH (Ertl et al 2002b and references therein). Thus, the occupancy of the $Y$ site greatly influences the distortion of the $Z$ site with which it shares edges. Only a few tourmalines with relatively high amounts of $Y$-site cations with a $3+$ charge $\left(\mathrm{Fe}^{3+}\right.$ and $\left.\mathrm{Al}^{3+}\right)$ do not fit the linear correlation. These samples include fluor-buergerite, in which $\mathrm{O} 3$ is occupied mainly by $\mathrm{O}^{2-}$ (Dyar et al. 1998), and oxy-rossmanite (Ertl et al. 2005) and olenite (Ertl et al. 2012), where some $\mathrm{O}^{2-}$ occupies the $\mathrm{O} 3$ site. The $\Delta_{\text {oct }}$ values vary between 0.34 and 0.48 (Ertl et al. 2002b).

As mentioned above, the $\mathrm{ZO}_{6}$ octahedron displays triclinic metrics with three variable $\mathrm{O} 3-Y-\mathrm{O} 7$ ', O6-Z-O7, O8-Z-O8' sizes. Therefore, the metrics of the $Z_{6}$ octahedron compared to an ideal undistorted octahedron should be expressed by three ratios: $\mathrm{O}_{-}-Y_{-}$ O7'/O6-Z-O7, O3-Y-O7'/O8-Z-O8' and O6-Z-O7/ O8-Z-O8'.

Schorl and dravite samples display similar trends of an O3-Y-O7'/O6-Z-O7 increase and O6-Z-O7/O8 -Z-O8' decrease with an increasing $\mathrm{Al}$ and $\mathrm{Fe}$ (Fig. 13). Because usually no significant proportion of $\mathrm{Fe}^{2+}$ enters the $Z$ site (Bačík 2015), these trends can be attributed to Al solely. In case of $\mathrm{Mg}$, the relationships are reverse, which means that $\mathrm{Mg}$ is negatively correlated to $\mathrm{O} 3-\mathrm{Y}-\mathrm{O} 7^{\prime} / \mathrm{O} 6-\mathrm{Z}-\mathrm{O} 7$ and positively to the $\mathrm{O} 6-Z-\mathrm{O} 7 / \mathrm{O} 8-Z-\mathrm{O} 8$ ' ratio (Fig. 13). Consequently, variations in metrics can be related to an $\mathrm{Al}-\mathrm{Mg}$ substitution at the $Z$ site. Interestingly, there is no clear correlation between the $\mathrm{O} 3-Y-\mathrm{O} 7^{\prime} / \mathrm{O} 8-Z-\mathrm{O} 8^{\prime}$ ratio and the content of any studied cation. This suggests that expansion and compression in these directions are regular and the octahedral metrics is changing due to the irregularity in the $\mathrm{O} 6-\mathrm{Z}-\mathrm{O} 7$ direction and mostly by the $Z-\mathrm{O} 6$ bond.

This can also explain the behaviour in elbaite and olenite samples. In elbaite, the $Z-\mathrm{O} 6$ bond is the shortest because the Al-O bond of the $Z$ site which is (almost) fully occupied by $\mathrm{Al}$ is distinctly stronger (ideally 0.5 $v u$ ) than the $\mathrm{Li}-\mathrm{O}$ bond $(0.17 v u)$ of the $\mathrm{YO}_{6}$ octahedron. Therefore, elbaite samples display the largest compression in the $\mathrm{O} 6-\mathrm{Z}-\mathrm{O} 7$ direction and thus also, the octahedral irregularity of all studied tourmalines. This is in agreement with the observation of the largest distortion of the $Y_{6}$ octahedron in elbaite samples. Consequently, the significant differences in charge of $\mathrm{Li}^{+}$and $\mathrm{Al}^{3+}$ and their bond valence result in a relatively large bond-length irregularity of both octahedra to accommodate these cations.

This is different in olenite samples, in which $>8$ apfu $\mathrm{Al}$ occupies the octahedra. The proportion of ${ }^{Y} \mathrm{Al}$ increases with balancing of the bond valences between $Z-\mathrm{O} 6$ and $Y-06$. Therefore, the compression of the $Z_{6}$ octahedron stops and then it starts to expand in $\mathrm{O} 6-Z-\mathrm{O} 7$ direction with increasing $\mathrm{Al}$, while it continues with a relatively regular compression in the other directions. The decrease of the $Z-\mathrm{O} 7$ bond length goes hand in hand with an increase of $Z-\mathrm{O} 6$, resulting in a consequent decrease of the $\mathrm{ZO}_{6}$ distortion. All $\mathrm{ZO}_{6}$ metrics are shifting towards 1.00 representing an ideal octahedron.

As expected, "buergerite" samples (fluor-buergerite, buergerite) are completely different. Comparing $Z-\mathrm{O} 7$ and both $Z-\mathrm{O} 8$ bond lengths, such tourmalines are in the general trend with schorl and dravite samples (Fig. 9), because these bonds are relatively limited in bond-valence variations due to their neighbourhood with high-valence bonds ( $\mathrm{Si}-\mathrm{O}, \mathrm{B}-\mathrm{O})$. The $\mathrm{Z}-\mathrm{O} 3$ bond is distinctly shorter due to $\mathrm{O}^{2-}$ occupancy at the $\mathrm{O} 3$ site. This is balanced by weakening and elongation of $Z-06$. Furthermore, these effects are accompanied by a strengthening of $Y-\mathrm{O} 6$ due to $\mathrm{Fe}^{3+}$ at the $Y$ site. Consequently, the $Z_{6}$ octahedron exhibits a very low irregularity, which is close to the ideal value of 1.00 (Fig. 13).

\section{Conclusions}

The metrics of octahedra in tourmalines result from wellbalanced and intertwined relations among cations. These are based on bond-valence variations due to different charges of occupying cations and anions. The influence of the $\mathrm{O} 1$ and $\mathrm{O} 3$ occupancy on the octahedral sites was already described. However, more significant on the octahedral metrics are the $Y$ - and $Z$-site cations. The irregularity at these sites is larger, when the difference in the charge of the occupying cations is larger. Elbaite samples with the largest charge difference between $\mathrm{Li}$ and $\mathrm{Al}$ display the largest irregularity of both octahedra. In contrast, "buergerite" samples (fluor-buergerite, buergerite) with trivalent $\mathrm{Fe}$ and $\mathrm{Al}$ show only small irregularity of octahedral sites closely approaching ideal octahedral metrics in both cases. These variations mainly occur at the shared edge of the $\mathrm{ZO}_{6}$ and $\mathrm{YO}_{6}$ octahedra - not only at the $\mathrm{O} 3$, but also at $\mathrm{O} 6$ site. This demonstrates the problems of the rigid-sphere ionic model for the description of some structural issues. Moreover, effects of internal geometry of atomic shells should be considered - such as Jahn-Teller distortion, which can be the critical factor for the cation occupancy. Mainly $\mathrm{Fe}^{2+}$ but also $\mathrm{Mn}^{3+}$ (which was not addressed here) can be very specific in favour of the $\mathrm{YO}_{6}$ octahedron.

Acknowledgements. Author thanks Jan Cempírek for editorial handling and two anonymous reviewers for their detailed reviews which improved the quality of this work. This work was supported by the Slovak 
Research and Development Agency under the contracts No. APVV-14-0278, APVV-15-0050 and APVV-170134, and the Ministry of Education of Slovak Republic grant agency under the contracts VEGA-1/0079/15 and VEGA-1/0499/16.

Electronic supplementary material. Supplementary Tables S1-S3 and Figures S1-S5 for this paper are available online at the Journal web site (http://dx.doi.org/10.3190/ jgeosci.260).

\section{References}

BAČ́́K P (2015) Cation ordering in octahedral sites in tourmalines of schorl-dravite series. Canad Mineral 53: 571-590

Bačík P, Fridrichová J, Uher P, PrŠEK J, OndREJKa M (2014) Crystal chemistry of gadolinite-datolite group silicates. Canad Mineral 52: 625-642

BARTON R JR (1969) Refinement of the crystal structure of buergerite and the absolute orientation of tourmalines. Acta Crystallogr B25: 1524-1533

Bloodaxe ES, Hughes JM, Dyar MD, Grew ES, Guidotti CV (1999) Linking structure and chemistry in the schorldravite series. Amer Miner 84: 922-928

Bosi F (2013) Bond-valence constraints around the $\mathrm{O} 1$ site of tourmaline. Mineral Mag 77: 343-351

BosI F (2017) Tourmaline structure and crystal chemistry. In: Cempí́rek J, Novák M, Gadas P (eds) Tourmaline 2017, International Symposium, Book of Abstracts. Masaryk University, Brno, pp 12-13

Bosi F, LuCCHESI S (2004) Crystal chemistry of the schorldravite series. Eur J Mineral 16: 335-344

Bosi F, Skogby H (2013) Oxy-dravite, $\mathrm{Na}\left(\mathrm{Al}_{2} \mathrm{Mg}\right)\left(\mathrm{Al}_{5} \mathrm{Mg}\right)$ $\left(\mathrm{Si}_{6} \mathrm{O}_{18}\right)\left(\mathrm{BO}_{3}\right)_{3}(\mathrm{OH})_{3} \mathrm{O}$, a new mineral species of the tourmaline supergroup. Amer Miner 98: 1442-1448

Bosi F, LuCCHESI S, REZNITSKII L (2004) Crystal chemistry of the dravite-chromdravite series. Eur J Mineral 16: 345-352

Bosi F, Reznitskit L, HÅlenius U, Skogby H (2017) Crystal chemistry of Al-V-Cr oxy-tourmalines from Sludyanka Complex, Lake Baikal, Russia. Eur J Mineral 29: $457-472$

Brown ID (2002) The Chemical Bond in Inorganic Chemistry. The Bond Valence Model. Oxford University Press, Oxford, pp 1-270

Brown ID (2013) Bond valence parameters file, bvparm2013.cif.txt. Posted on October 16, 2013; accessed on May 15,2018, at http://www.iucr.org/resources/data/ datasets/bond-valence-parameters

BRown ID, SHANNON RD (1973) Empirical bond-strengthbond-length curves for oxides. Acta Crystallogr A29: 266-282
BuRns RG (2005) Mineralogical Applications of Crystal Field Theory. Cambridge University Press, Cambridge, pp 1-576

Burns RG, StRENS RGJ (1967) Structural interpretation of polarized absorption spectra of the Al-Fe-Mn-Crepidotes. Mineral Mag 36: 204-226

Burns PC Hawthorne FC (1996) Static and dynamic JahnTeller effects in $\mathrm{Cu}^{2+}$ oxysalt minerals. Canad Mineral 34: 1089-1105

Cempírek J, Houzar S, Novák M, Groat LA, Selway JB, ŠreIN V (2013) Crystal structure and compositional evolution of vanadium-rich oxy-dravite from graphite quartzite at Bítovánky, Czech Republic. J Geosci 58: 149-162

Donnay G, Buerger MJ (1950) The determination of the crystal structure of tourmaline. Acta Crystallogr 3: 5-12

Downs RT, Hall-Wallace M (2003) The American Mineralogist Crystal Structure Database. Amer Miner 88: $247-250$

Dyar MD, TAYlor ME, Lutz TM, Francis CA, Guidotti CV, WISE M (1998) Inclusive chemical characterization of tourmaline: Mössbauer study of Fe valence and site occupancy. Amer Miner 83: 848-864

Ertl A, Hughes JM, MarLer B (2002a) Empirical formulae for the calculation of $\langle T-\mathrm{O}>$ and $X-\mathrm{O} 2$ bond lengths in tourmaline and relations to tetrahedrally-coordinated boron. Neu Jb Mineral, Mh 2002: 548-557

Ertl A, Hughes JM, Pertlik F, Foit FF Jr, Wright SE, Brandstätter F, Marler B (2002b) Polyhedron distortions in tourmaline. Canad Mineral 40: 153-162

Ertl A, Hughes JM, Brandstatter F, Dyar MD, Prasad PSR (2003) Disordered Mg-bearing olenite from a granitic pegmatite at Goslarn, Austria: a chemical, structural, and infrared spectroscopic study. Canad Mineral 41: 1363-1370

Ertl A, Rossman GR, Hughes JM, Prowatke S, Ludwig T (2005) Mn-bearing "oxy-rossmanite" with tetrahedrallycoordinated Al and B from Austria: structure, chemistry, and infrared and optical spectroscopic study. Amer Miner 90: 481-487

Ertl A, Hughes JM, Prowatke S, Ludwig T, Prasad PSR, Brandstätter F, Körner W, Schuster R, Pertlik F, MarsChall H (2006) Tetrahedrally coordinated boron in tourmaline from the liddicoatite-elbaite series from Madagascar: structure, chemistry, and infrared spectroscopic studies. Amer Miner 91: 1847-1856

Ertl A, Hughes JM, Prowatke S, Ludwig T, BrandstätTER F, KÖRNER W, DyAR MD (2007) Tetrahedrally-coordinated boron in Li-bearing olenite from "mushroom" tourmaline from Momeik, Myanmar. Canad Mineral 45: 891-899

Ertl A, Tillmanns E, Ntaflos T, Francis C, Giester G, Körner W, Hughes JM, Lengauer C, Prem M (2008) 
Tetrahedrally coordinated boron in Al-rich tourmaline and its relationship to the pressure-temperature conditions of formation. Eur J Mineral 20: 881-888

Ertl A, Mali H, Schuster R, Körner W, Hughes JM, BRANDSTÄTtER F, TILLMANNS E (2010) Li-bearing, disordered $\mathrm{Mg}$-rich tourmalines from the pegmatitemarble contact from the Austroalpine basement units (Styria, Austria). Mineral Petrol 99: 89-104

Ertl A, Kolitsch U, Dyar MD, Hughes JM, Rossman GR, Pieczka A, Henry DJ, Pezzotta F, Prowatke S, LenGaUer CL, Körner W, Brandstätter F, Francis CA, Prem M, Tillmanns E (2012) Limitations of $\mathrm{Fe}^{2+}$ and $\mathrm{Mn}^{2+}$ site occupancy in tourmaline: evidence from $\mathrm{Fe}^{2+}$ and $\mathrm{Mn}^{2+}$-rich tourmaline. Amer Miner 97: 1402-1416

Ertl A, Vereshchagin OS, Giester G, Tillmanns E, Meyer H-P, Ludwig T, RozhdestVenskaya IV, FranKKAMENETSKAYA OV (2015) Structural and chemical investigation of a zoned synthetic $\mathrm{Cu}$-rich tourmaline. Canad Mineral 53: 209-220

Ertl A, Baksheev IA, Giester G, Lengauer CL, ProkoFIEV VYU, Zorina LD (2016) Bosiite, $\mathrm{NaFe}^{3+}{ }_{3}\left(\mathrm{Al}_{4} \mathrm{Mg}_{2}\right)$ $\left(\mathrm{Si}_{6} \mathrm{O}_{18}\right)\left(\mathrm{BO}_{3}\right)_{3}(\mathrm{OH})_{3} \mathrm{O}$, a new ferric member of the tourmaline supergroup from the Darasun gold deposit, Transbaikalia, Russia. Eur J Mineral 28: 581-591

FAYE GH (1968) The optical absorption spectra of iron in six-coordinate sites in chlorite, biotite, phlogopite and vivianite: some aspects of pleochroism in the sheet silicates. Canad Mineral 9: 403-425

Fort FF JR, Rosenberg PE (1979) The structure of vanadium-bearing tourmaline and its implications regarding tourmaline solid solutions. Amer Miner 64: 788-798

Fridrichová J, Bačík P, ERTL A, WiLDNER M, MigLIERINI M (2017) Crystal chemistry and Jahn-Teller distortion of $\mathrm{Mn}^{3+}$-occupied octahedra in red beryl from Utah. J Mol Struct 1152: 79-86

GaGnÉ OC, Hawthorne FC (2015) Comprehensive derivation of bond-valence parameters for ion pairs involving oxygen. Acta Crystallogr B71: 562-578

GoodenOUGH JB (1964) Jahn-Teller distortions induced by tetrahedral-site $\mathrm{Fe}^{2+}$ ions. J Phys Chem Solids 25: 151-160

Grice JD, ERCIT TS (1993) Ordering of Fe and Mg in the tourmaline crystal structure: the correct formula. $\mathrm{Neu} \mathrm{Jb}$ Mineral, Abh 165: 245-266

Hamburger GE, Buerger MJ (1948) The structure of tourmaline. Amer Miner 33: 532-540

HAWTHORNE FC (1996) Structural mechanisms for lightelement variations in tourmaline. Canad Mineral 34: 123-132

HAWTHORNE FC (2002) Bond-valence constraints on the chemical composition of tourmaline. Canad Mineral 40: 789-797

Hawthorne FC, Henry DJ (1999) Classification of the minerals of the tourmaline group. Eur J Mineral 11: 201-215
Hawthorne FC, MacDonald DJ, Burns PC (1993) Reassignment of cation site-occupancies in tourmaline: $\mathrm{Al}-\mathrm{Mg}$ disorder in the crystal structure of dravite. Amer Miner 78: 265-270

Henry DJ, Dutrow BL (1996) Metamorphic tourmaline and its petrologic applications. In: Grew ES, ANOVITZ LM (eds) Boron: Mineralogy, Petrology and Geochemistry. Mineralogical Society of America Reviews in Mineralogy 33: 503-557

Henry DJ, Novák M, Hawthorne FC, Ertl A, Dutrow BL, Uher P, Pezzotta F (2011) Nomenclature of the tourmaline-supergroup minerals. Amer Miner 96: 895-913

Hughes JM, Ertl A, Dyar MD, Grew ES, Wiedenbeck M, Brandstätter F (2004) Structural and chemical response to varying ${ }^{[4]} \mathrm{B}$ content in zoned Fe-bearing olenite from Koralpe, Austria. Amer Miner 89: 447-454

Ito J, HAFNER SS (1974) Synthesis and study of gadolinites. Amer Miner 59: 700-708

Ito T, SADANAGA R (1951) Fourier analysis of the structure of tourmalines. Acta Crystallogr 4: 5-12

JAHN H, TelLER E (1937) Stability of polyatomic molecules in degenerate electronic states. I. Orbital degeneracy. Proc R Soc London, Ser A Mat 161: 220-235

Kutzschbach M, Wunder B, Rhede D, Koch-Müller M, Ertl A, Giester G, Heinrich W, Franz G (2016) Tetrahedral boron in natural and synthetic high-pressure tourmaline: evidence from Raman spectroscopy, EMPA, and single-crystal XRD. Amer Miner 101: 93-104

Kutzschbach M, Wunder B, Krstulovic M, Ertl A, Trumbull R, Rocholl A, Giester G (2017) First high-pressure synthesis of rossmanitic tourmaline and evidence for the incorporation of $\mathrm{Li}$ at the $\mathrm{X}$-site. Phys Chem Miner 44: 353-363

Kyono A, Gramsch SA, Yamanaka T, IkUta D, Ahart M, Mysen BM, Mao H-K, Hemley RJ (2012) The influence of the Jahn-Teller effect at $\mathrm{Fe}^{2+}$ on the structure of chromite at high pressure. Phys Chem Miner 39: 131-141

Lussier AJ, Aguiar PM, Michaelis VK, Kroeker S, Herwig S, AbDu Y, Hawthorne FC (2008) Mushroom elbaite from the Kat Chay mine, Momeik, near Mogok, Myanmar: I. Crystal chemistry by SREF, EMPA, MAS NMR and Mössbauer spectroscopy. Mineral Mag 72: 747-761

Lussier AJ, Aguiar PM, Michaelis VK, Kroeker S, HAWTHORNE FC (2009) The occurrence of tetrahedrally coordinated $\mathrm{Al}$ and $\mathrm{B}$ in tourmaline: an ${ }^{11} \mathrm{~B}$ and ${ }^{27} \mathrm{Al}$ MAS NMR study. Amer Miner 94: 785-792

Makovicky E, Balic-Zunic T (1998) New measure of distortion for coordination polyhedra. Acta Crystallogr B54: 766-773

Marschall HR, Ertl A, Hughes JM, McCammon C (2004) Metamorphic Na- and OH-rich disordered dravite 
with tetrahedral boron, associated with omphacite, from Syros, Greece: chemistry and structure. Eur J Mineral 16: $817-823$

Nishio-Hamane D, Minakawa T, Yamaura J-I, Oyama T, Ohnishi M, Shimobayashi N (2014) Adachiite, a Si-poor member of the tourmaline supergroup from the Kiura mine, Oita Prefecture, Japan. J Mineral Petrol Sci 109: 74-78
Robinson K, GibBs GV, RibBe PH (1970) Quadratic elongation: a quantitative measure of distortion in coordination polyhedra. Science 172: 567-570

SHANNON RD (1976) Revised effective ionic radii and systematic studies of interatomic distances in halides and chalcogenides. Acta Crystallogr A32: 751-767

TipPe A, Hamilton WC (1971) A neutron-diffraction study of the ferric tourmaline buergerite. Amer Miner 56: 101-113 